\title{
Dispersão decisória, centralidade política e entropia burocrática: mitigando custos transacionais na gestão pública
}

\author{
Alexander Cambraia N. Vaz $^{1}$ (D)
}

\begin{abstract}
O artigo investiga os impactos de capacidades burocráticas e sociopolíticas nos processos de formulação e implementação de políticas públicas. Realiza-se estudo comparativo de quatro instituições do poder Executivo federal brasileiro, buscando, através de seus respectivos percursos históricos de formação, elementos explicativos para sua situação atual em termos dessas capacidades. Em adição, realiza-se estudo de programas desenvolvidos por essas instituições, entrevendo em que sentido seu status corrente de capacidades tende a influenciar o desenvolvimento de cada um deles. A análise evidencia que a área temática de atuação dos órgãos/programas tem importante influência no potencial de desenvolvimento das capacidades estudadas. Ademais, o desenvolvimento conjunto dessas últimas parece levar à obtenção de resultados satisfatórios no desenvolvimento de políticas de uma forma geral.
\end{abstract}

Palavras-chave: capacidades estatais; capacidades burocráticas; capacidades políticas; interfaces socioestatais; desenvolvimento socioeconômico

\section{Introdução}

Não raro, a discussão sobre os determinantes dos resultados de políticas públicas se apresenta com destaque na literatura que analisa as ações e empreendimentos de cunho governamental (Leftwich, 1998). Autores de distintas áreas, como a ciência política (Hendrix, 2010), a sociologia (Skocpol, 1979), entre outras, vêm refletindo conjuntamente sobre o tema. Uma das posições clássicas no debate encontra guarida na chamada hipótese weberiana estatal (Evans e Rauch, 2000), que associa a efetividade de atuação do Estado à presença de uma burocracia altamente profissionalizada, dotada de habilidades técnicas para implementação de políticas e guarnecida de recursos e autonomia operacional no âmbito das instituições públicas (Chang, 2003; Evans e Heller, 2013). Quanto maior o reforço desses ativos, ou dessas capacidades burocráticas, maiores seriam os potenciais

\footnotetext{
${ }^{1}$ Instituto Brasiliense de Direito Público, Escola de Administração Pública, Brasília (DF), Brasil. Faculdade de Filosofia e Ciências Humanas, Universidade Federal de Minas Gerais, Belo Horizonte (MG), Brasil. E-mail: <cambraia04@gmail.com>.
} 
de gestão e de apresentação de resultados satisfatórios nas operações estatais (Howlett e Ramesh, 2003).

Neste artigo, iremos não só abordar esse argumento, como também nos apoiar nele, mas buscando avançar com base na discussão sobre a influência de outra dimensão concorrente no processo, a qual chamaremos de capacidade socioestatal. Essa dimensão diz respeito ao tipo e grau de contato que os agentes político-burocráticos estabelecem com atores não governamentais no âmbito dos programas e projetos sob sua competência e supervisão. É a partir de sua combinação com o componente de capacidade burocrática que os resultados obtidos nas ações estatais podem ser evidenciados em termos de variação e mudança. Em particular, sugere-se que essa conexão tende a mitigar os efeitos dos custos transacionais associados aos processos de gestão e implementação de políticas públicas, criando as condições e circunstâncias mais propícias à obtenção de melhorias relativas nos resultados das operações governamentais. Para os fins deste artigo, foram elegidos três custos transacionais frequentemente associados à dinâmica pública decisória (Leftwich, 1998): a dispersão decisória, a centralidade política e a entropia burocrática.

O artigo se ancora em duas estratégias de análise. Primeiro, uma investigação ampla de órgãos públicos através do cruzamento de indicadores de ambas as dimensões vis-à-vis resultados apresentados por programas erigidos sob suas respectivas alçada e abrangência de atuação. Logo em seguida, realiza-se uma análise qualitativa de quatro programas elegidos em meio ao rol investigado, visando compreender a dinâmica pela qual os custos transacionais são afetados, ou mitigados, pelo entrelaçamento das dimensões em pauta. Por objeto de estudo, elegemos órgãos e programas da administração direta do poder Executivo federal brasileiro. Os dados, referentes ao período de 2004 a 2009, foram coletados através de documentos oficiais, registros administrativos (o SIGPlan - Sistema de Informações Gerenciais e de Planejamento do Plano Plurianual -, o banco de filiações partidárias do Tribunal Superior Eleitoral e a base de servidores federais da ControladoriaGeral da União), além de entrevistas em profundidade realizadas com gestores responsáveis por programas desenvolvidos em cada instituição analisada.

Em adição a essa breve introdução, o texto se organiza em mais quatro seções. Na primeira, "Resultados em políticas públicas: entre capacidade burocrática e eficácia socioestatal", discutem-se as dimensões de análise aqui elencadas, com foco na importância de sua articulação no âmbito da gestão e nos resultados apresentados pela administração estatal na operacionalização de políticas públicas. Na segunda, "Capacidades e resultados efetivos em políticas públicas", são exploradas as relações entre as capacidades burocrática e socioestatal, buscando aferir seus respectivos graus de determinância em relação aos resultados apontados. A terceira seção, "Custos transacionais e o desenvolvimento institucional", se dedica a um estudo comparativo de programas desenvolvidos por órgãos elegidos no conjunto investigado, buscando identificar as dinâmicas operacionais específicas que atuam na consolidação e na operação das dimensões aqui referidas - em especial, a forma pela qual os custos transacionais são 
afetados pelo desenvolvimento de cada uma delas. A quarta e última seção, "À guisa de conclusão", é dedicada às considerações finais.

\section{Resultados em políticas públicas: entre capacidade burocrática e eficácia socioestatal}

As análises e estudos acerca do papel do Estado na gestão pública nos informam sobre a relevância do ator para a promoção do desenvolvimento das sociedades de uma forma geral (List, 1986; Ribeiro et al., 2006; Bresser-Pereira, 2011; Albuquerque, 2013). Uma das questões que se destacam no debate concerne à capacidade do Estado para operacionalizar as medidas necessárias à concretização desse processo vis-à-vis o contexto de complexidade que cerca a dinâmica decisória base das políticas que deverão ser erigidas no âmbito de sua estruturação (Evans, 2011). Essa complexidade se caracteriza por uma negociação de cunho coletivo e conflituoso, cujo cerne envolve elementos que tendem a desafiar sobremaneira as perspectivas de geração de resultados no campo, que são os chamados custos transacionais (Howlett e Ramesh, 2003). Grosso modo, os custos transacionais se referem àqueles custos que estão além da fase de desenho e planejamento das políticas interventivas, associando-se às tarefas de negociação e garantia de cumprimento dos acordos necessários para a efetivação de cada uma delas (Fiani, 2011). Entre os custos transacionais, neste artigo, trataremos apenas da dispersão decisória, da centralidade política e da entropia burocrática.

A dispersão decisória diz respeito às negociações que englobam diferentes atores e instâncias de tomada de decisão para o tratamento de determinado assunto público (Miguel, 2005; Jann e Wegrich, 2007). Via de regra, os processos decisórios em políticas públicas envolvem, por um lado, instâncias distintas dentro da própria burocracia, as quais necessitam se manifestar no âmbito dos procedimentos e protocolos administrativos erigidos na seara (Cardoso Jr., 2012; Fiani, 2013). Afinal, a política cinge, vale dizer, diversas áreas governamentais para sua consecução e não apenas aquela específica a partir da qual tenha porventura surgido a iniciativa de estruturá-la (Wise, 2004). Em adição, por outro lado, fora da burocracia existe ainda uma miríade de atores interessados no desenvolvimento da política, cada qual buscando influenciá-la à sua maneira (Santos e Avritzer, 2003; Pires e Gomide, 2016). O principal custo advindo desse processo se caracteriza pelos significativos esforços de coordenação e harmonização de interesses e preferências, não raro antagônicos, através da institucionalização customizada de regras e normativas, a serem desenhadas especificamente para cada tipo de dinâmica e/ou estrutura de interação concebidas (Przeworski, Stokes e Manin, 1999).

A centralidade política concerne à importância que a área temática do programa público tem para o projeto político dos grupos que ocupam posições de poder (Brasil, 2013; Lavalle, Voigt e Serafim, 2016). Ela se materializa na concentração de recursos e fluxos de ação àquelas áreas que mais se aderem aos interesses e fins políticos desses grupos, 
interferindo diretamente nas atividades e operações dessas áreas (Cardoso Jr., 2014). O processo decisório passa a se ancorar muito menos no escrutínio de aportes e informações objetivas - capazes de guiar de maneira mais racional a ação estatal - e muito mais num pragmatismo ativo de fundo político-partidário (Peres, 2007; Boschi e Gaitán, 2009). Esse pragmatismo tem por origem os constrangimentos advindos não só de compromissos eleitorais previamente assumidos com outros grupos políticos, mas, também, da pura e simples competição de lastro partidário (Peruzzotti, 2007). O custo advindo desse processo tange ao alto grau de casuísmo na elaboração e gestão de políticas públicas, tornando-as muito mais políticas circunstanciais de governo e muito menos políticas efetivas de Estado (Avritzer, 2015; Faria, 2017).

A entropia burocrática, por fim, diz respeito ao grau de contato que determinada burocracia mantém com atores externos - burocratas ou não - e que tende a influenciar as decisões tomadas internamente (Campos, 1995; Weber, 2002; Tenório, 2003). Quanto maior sua intensidade, maiores as chances de essas decisões terem por referência e padrão apenas as características dessa própria burocracia, gerando um movimento de retroalimentação de ideias e operações eminentemente internas (Herscovici, 2005). Se, por um lado, esse movimento tende a acelerar o processo de tomada de decisão (North, 2003), por outro, pode fazer com que a instituição pública sofra uma rápida degradação no seu potencial de ação e intervenção, uma vez que não consegue buscar novas perspectivas para o tratamento das questões sob sua supervisão (Barrios, 2008). O custo gerado nesse processo se caracteriza justamente por essa perda de potencial de ação, com a possível transformação da burocracia num fim em si mesma (Campos, 1995).

Com base na análise de todos esses elementos, não é difícil perceber o grau de determinância que os custos transacionais impõem ao contexto a que o agente estatal está sujeito no âmbito de suas intervenções. Eles passam mesmo a agir como definidores do seu desempenho nas práticas de desenho e implementação de políticas públicas, impactando o potencial de entregas que é capaz de fazer na área (Herscovici, 2005; Edigheji, 2010). Por corolário, o desempenho do ator na geração e implementação dessas políticas fica sobremaneira dependente das formas pelas quais ele passa a lidar com esses custos. E, nessa linha, o desafio passa a ser justamente compreender quais as condições que tendem a lhe propiciar melhores chances de se sobrepor a tais custos e lhe ajudar, por consequência, a aperfeiçoar seu potencial de operação e de apresentação de resultados nessa seara (Skocpol, 1979; Hendrix, 2010).

Uma das posições clássicas nesse debate encontra guarida nas discussões em torno das chamadas capacidades burocráticas estatais, que seriam aqueles ativos e recursos administrativos disponíveis ao Estado cujas composição e variação tenderiam a impactar diretamente as suas perspectivas operacionais e de atuação efetivas (Evans e Rauch, 2000). Esses ativos se consubstanciariam em elementos associados ao desempenho do ator, como o grau de profissionalização dos seus corpos burocráticos, o nível de capacidade técnica engendrado para a compilação de políticas, o volume e o tipo 
de recursos disponíveis para a sua operacionalização, dentre outros (Chang, 2003). Ocorre que, apesar de ter se constituído, ao longo do tempo, como um termo clássico e frequentemente utilizado no âmbito das pesquisas, investigações e análises empreendidas especialmente nas áreas da administração e da gestão pública estatais, o conceito tem se revelado, em grande medida, fonte premente e não desprezível de dissenso e divisão entre os pesquisadores e practioners ligados a essas áreas (Gomide, Pereira e Machado, 2017).

A ideia de capacidades burocráticas vem sendo apropriada por uma variedade de scholars advindos de setores e campos de estudos distintos, como a ciência política (Evans, 1995), a sociologia (Skocpol, 1979), as relações internacionais (Thies, 2010), a economia (Besley e Persson, 2009), a administração pública (Weber, 2002), entre outros. Cada área tende a utilizá-la com fins e vieses que são frequentemente distintos entre si, necessitando, por isso, de definições que nem sempre guardam qualquer grau de similaridade (Pires e Gomide, 2016). De acordo com Hendrix (2010), essa diversidade de definições e atributos tende a tornar o conceito um constructo teórico-analítico no mínimo improdutivo, já que não Ihe confere referências válidas para a sua consecução. Além disso, a essa miríade de caracterizações são atribuídas, em geral, diferentes classes e tipos de variáveis e indicadores, com fulcro na sua operacionalização, o que tem por principal consequência a aferição de distintos resultados quando da mensuração de um mesmo fenômeno a partir de um mesmo tipo e/ou conjunto de objetos (Gomide, Pereira e Machado, 2017). Ou seja, mesmo quando analisamos a perspectiva de operacionalização efetiva do conceito, observamos parco consenso também no que tange ao seu potencial de efetiva estruturação analítico-metodológica (Kocher, 2010).

Existe ainda outro embaraço importante relacionado à mensuração dessas capacidades, que diz respeito à sua confusão com variáveis que, no mais das vezes, cumprem papel interveniente nas suas definições (Painter e Pierre, 2005). Frequentemente o conceito tende a ser descrito a partir do sistema político adotado em determinado país (White, 1998), seus níveis de desenvolvimento econômico (Johnson, 1985; Chang, 1995), além das regras que asseguram a atuação dos agentes privados no âmbito e na esteira dos mercados (North, 2003). Em geral, os resultados desses tipos de análise tendem a encontrar uma correlação significativa entre o desempenho do governo e o desempenho da própria economia, mas são incapazes de elucidar o papel e o impacto das capacidades burocráticas uma vez já dados e estabelecidos os diferentes níveis e vieses de funcionamento dos substratos de fundo e caráter socioeconômicos (Hendrix, 2010; Evans, 2011; Bresser-Pereira, 2011; Rauch e Evans, 2011).

É a partir da constatação de todos esses imbróglios que tomamos por base, para os fins deste artigo, as disposições clássicas de Evans, Rueschemeyer e Skocpol (1985) para a ideia das capacidades burocráticas. Os autores esboçam um modelo de representação da estrutura burocrática do Estado a partir de um viés minimalista e funcional, que define o conceito como uma burocracia sustentada e caracterizada pelos arquétipos da profissionalização e da capacidade de atuar com dada autonomia na gestão 
das políticas públicas. A profissionalização estaria relacionada ao grau de especialização dos técnicos e funcionários em determinado campo de atuação do Estado e marcado por políticas claras de treinamento, remuneração e progressão funcional. Já a autonomia estaria atrelada à possibilidade de atuação dos agentes públicos de maneira livre e protegida de interesses eminentemente particularistas, porque capazes de colocar em risco a própria administração das políticas sob suas respectivas competência e supervisão.

O pressuposto principal que embasa a proposição dos autores é de que os programas podem ser dotados de recursos humanos altamente qualificados, mas, ao mesmo tempo, altamente comprometidos, por exemplo, com arranjos de determinados interesses partidários. Daí a importância de analisar as dimensões de profissionalização e autonomia conjuntamente, ainda que elas possam variar de maneira independente 2 (Howlett e Ramesh, 2003). Essa forma de operacionalização das capacidades burocráticas está também na base dos estudos e prognósticos de Evans e Rauch (2000), segundo os quais a substituição de arranjos patrimonialistas (Nunes, 1997) por estruturas burocratizadas de Estado seria condição para a garantia de efetividade na implementação de políticas públicas. A essa condição os autores imprimem a alcunha de hipótese weberiana do Estado (weberian State hypothesis) e sugerem um rol de categorias e definições teóricas capazes de conferir suporte à sua instrumentalização (Quadro 1):

\footnotetext{
2 Seguindo essa linha de arguição, Evans (2011) afirma que as capacidades burocráticas se consubstanciariam no potencial do Estado de combinar, ao mesmo tempo, autonomia e parceria com os diversos grupos envolvidos nos processos de gestão de políticas públicas. Sua base justificativa é estruturada em torno dos principais pressupostos da literatura que vêm lidando com o tema, como a conformação de um corpo burocrático coeso, especializado e competente para a gestão dos projetos nacionais (Evans, 1995).
} 
Quadro 1

Dimensões de análise estruturantes do conceito de capacidade burocrática

\begin{tabular}{|c|c|c|c|}
\hline Dimensão & Subdimensão & Categoria & Descrição \\
\hline \multirow{7}{*}{$\begin{array}{l}\text { Capacidades } \\
\text { burocráticas }\end{array}$} & \multirow{5}{*}{$\begin{array}{c}\text { Profissionalização } \\
\text { Relacionada ao grau de } \\
\text { especialização dos técnicos e } \\
\text { funcionários em determinado campo } \\
\text { de atuação do Estado - distinto da } \\
\text { especialização de outros campos de } \\
\text { atuação - e marcado por políticas } \\
\text { claras de treinamento, remuneração } \\
\text { e progressão funcional. }\end{array}$} & $\begin{array}{l}\text { Mandato } \\
\text { principal da } \\
\text { carreira }\end{array}$ & $\begin{array}{l}\text { Refere-se ao envolvimento, no planejamento e na gestão de } \\
\text { determinado programa, de técnicos que pertençam a alguma } \\
\text { carreira pública que esteja ligada à sua temática de } \\
\text { execução. }\end{array}$ \\
\hline & & $\begin{array}{l}\text { Mandato de } \\
\text { especialista }\end{array}$ & $\begin{array}{c}\text { Refere-se ao envolvimento, no planejamento e na execução } \\
\text { de determinado programa, de técnicos que, embora não } \\
\text { pertençam à carreira específica mais prementemente ligada } \\
\text { a esse programa, pertencem a alguma outra carreira } \\
\text { especializada na sua temática de execução e que detém } \\
\text { caráter transversal. }\end{array}$ \\
\hline & & $\begin{array}{l}\text { Longevidade } \\
\text { no serviço } \\
\text { público }\end{array}$ & $\begin{array}{c}\text { Refere-se ao tempo em que os técnicos envolvidos em } \\
\text { determinado programa têm trabalhado não apenas no } \\
\text { serviço público, mas na temática desse programa e, em } \\
\text { especial, no próprio programa }\end{array}$ \\
\hline & & $\begin{array}{l}\text { Servidores } \\
\text { requisitados }\end{array}$ & $\begin{array}{l}\text { Refere-se ao envolvimento, no planejamento e na gestão de } \\
\text { determinado programa, de técnicos que são requisitados de } \\
\text { outras agências e órgãos, sem pertencimento a alguma } \\
\text { carreira nem experiência associadas à temática de execução } \\
\text { do programa. }\end{array}$ \\
\hline & & $\begin{array}{c}\text { Salários } \\
\text { competitivos }\end{array}$ & $\begin{array}{c}\text { Refere-se à média de remuneração dos técnicos envolvidos } \\
\text { na execução de determinado programa. }\end{array}$ \\
\hline & \multirow{2}{*}{$\begin{array}{c}\text { Autonomia } \\
\text { Atrelada à possibilidade de atuação } \\
\text { dos agentes públicos de maneira livre } \\
\text { e protegida de interesses } \\
\text { eminentemente particularistas, porque } \\
\text { capazes de colocar em risco a própria } \\
\text { administração das políticas públicas. }\end{array}$} & DAS políticos & $\begin{array}{c}\text { Refere-se ao envolvimento, no planejamento e na gestão de } \\
\text { determinado programa, de técnicos ocupantes de cargos } \\
\text { DAS (Direção e Assessoramento Superior), de livre } \\
\text { nomeação, mas sem pertencimento a alguma carreira } \\
\text { específica da administração pública. }\end{array}$ \\
\hline & & $\begin{array}{l}\text { Técnicos } \\
\text { políticos }\end{array}$ & $\begin{array}{l}\text { Refere-se ao envolvimento, no planejamento e na gestão de } \\
\text { determinado programa, de técnicos que trabalham em } \\
\text { determinado programa que são filiados a partidos políticos. }\end{array}$ \\
\hline
\end{tabular}

Fonte: Evans e Rauch (2000).

A depender da combinação dessas categorias, dadas como componentes das capacidades burocráticas, se fariam incrementadas ou diminuídas as chances do Estado de aperfeiçoar seus potenciais de gestão e, principalmente, de apresentação de resultados no âmbito da operacionalização das políticas públicas por ele eventualmente erigidas (Skocpol e Amenta, 1986; Ramesh e Howlett, 2016). Esse movimento, referendado especificamente para o caso dessas capacidades, se faria possível, sugere-se, em função da forma pela qual os custos transacionais seriam impactados a partir do seu desenvolvimento.

A dispersão decisória, por exemplo, cujo custo central recai, como visto, sobre a necessidade de coordenar a ação conjunta de agentes com interesses distintos e frequentemente conflitantes, teria seu peso minimizado na ação estatal, uma vez que os atores presentes nos processos de tomada de decisão seriam apenas aqueles exclusivamente elegidos pelo próprio Estado para negociação (Evans, 2011). Já para a centralidade política, cujo custo principal recai nos prognósticos de significativa ingerência política em decisões de apelo e caráter eminentemente técnico-administrativos, seu peso 
também seria minorado, uma vez que a força de composição e o esprit de corps das burocracias agiriam como constrangimentos a esse modo de intervenção nos trabalhos (Oliveira e Abrucio, 2011; Monteiro, 2013). Por fim, no que concerne à entropia burocrática, cujo custo central recai sobre a necessidade de promover maior abertura do Estado ao contato com outros atores no âmbito dos seus processos decisórios (como forma de reduzir o risco de degradação do seu próprio potencial de ação), ela mesma deixaria de ser uma questão abordada, pois que as possibilidades de interação técnica das burocracias já estariam tendentes a se restringir ao próprio corpo burocrático (Wise, 2004).

Ocorre que as investigações empíricas que serviram de base à composição da hipótese weberiana do Estado se estruturaram em torno de duas condições históricas bastante específicas: primeiro, a adoção, na maioria dos Estados tomados por objeto de investigação, de um sistema político diferente da democracia (Evans, 2004); e, segundo, mesmo nos casos estudados nos quais esse sistema foi adotado, o foco na sua concepção estrito-procedimental, voltada à instituição do voto como elemento exclusivo para resolução do problema agente-principal na política (Schumpeter, 1976; Leftwich, 1998). Sem embargo da relevância das contribuições teórico-analíticas trazidas à baila por essas investigações, as circunstâncias histórico-contextuais contemporâneas sob as quais o ator estatal tem sido instado a agir se recobrem de elementos condicionantes e balizadores que Ihes são efetiva e factualmente estranhos ( $V a z, 2015)$. A base normativo-operacional estruturadora dessas circunstâncias se pauta pela busca de um modelo de gestão de políticas públicas operacionalmente focado numa maior proximidade e contiguidade entre o Estado e o conjunto da população (Santos e Avritzer, 2003). O núcleo de expressão desse movimento se funda na exigência cada vez maior de transparência e responsividade no que toca às ações estatais, com os governos sendo cada vez mais demandados a partilhar com a sociedade o poder decisório que irá gerar as ações e as atividades delineadoras dos seus próprios projetos e ações (Miguel, 2005; Avritzer, 2009; Lavalle e Szwako, 2015; Faria, 2017).

Uma vez confrontada com esse contexto, a concepção clássica de ação estatal, embasada exclusivamente nas capacidades burocráticas como substrato executivo e instrumental do Estado, acaba por revelar sinais claros de limitação em sua concretude e factibilidade práticas (White, 1998; Evans, 2011). Sucede-se que tais capacidades se estruturam, via de regra, de maneira restrita à perspectiva de assunção de parcerias do ator com grupos econômicos de caráter exclusivamente privado (Evans, 1995), à mestria na gestão de conflitos entre tais grupos (Chang, 1995), bem como à busca de metainstituições capazes de, pragmaticamente, sistematizar seus respectivos processos de interação (North, 2003). Contudo, dada a nova conjuntura com a qual o ator estatal tem sido instado a agir, faz-se premente a necessidade de que ele passe a negociar e tratar com os diversos grupos que compõem o tecido social, para muito além daqueles de caráter exclusivamente econômico e supostamente estratégico aos projetos prioritários no seu âmbito operacional e de ação gerencial (Sintomer, 2010). 
Esse "novo" arcabouço operacional delineado para a ação estatal lhe exigiria, para além do aperfeiçoamento das capacidades burocráticas, o desenvolvimento, sugere-se, de capacidades socioestatais como forma de garantir legitimidade à sua laboração executiva. Essas capacidades socioestatais se expressariam, sobretudo, na busca constante por sinergias e concertações com os diversos movimentos e grupos da sociedade, a depender do campo temático objeto de trabalho do Estado. A este último, na verdade, caberia a tarefa de estabelecer interações com os diversos setores associados a seus projetos de desenvolvimento, independentemente de serem eles vinculados estritamente à esfera econômica, ou ligados a outras esferas de atuação social, como meio ambiente, proteção/seguridade social, educação, movimentos de base, entre outros (Evans e Rauch, 2000; Avritzer, 2009).

Ao tecerem análises nessa temática, Pires e Vaz (2014) afirmam que a interlocução Estado-sociedade segundo as disposições dessas capacidades é, de fato, passível de se concretizar - sobretudo institucionalmente - e que isso se daria sob a égide de pelo menos dois grandes prismas. O primeiro seria concernente ao âmbito da articulação coletiva, relativa ao envolvimento no processo de interação Estado-sociedade de atores de caráter grupal, dotados de demandas que poderiam ou não resultar em benefícios de ordem coletiva. Já o segundo estaria associado à negociação estritamente individual, caracterizando-se pela relação que os sujeitos estabeleceriam singularmente com o Estado, a partir de interesses cujos impactos teriam potencial de geração de benefícios estritamente individuais ou, ainda, holisticamente difusos.

A operacionalização de ambos os prismas, segundo os autores, se daria a partir do estabelecimento das chamadas interfaces socioestatais no âmbito das agências governamentais (Pires e Vaz, 2014). Estes seriam canais de contato entre Estado e sociedade materializados sob formatos distintos, variando os tipos de institucionalidades potencialmente presentes na relação Estado-sociedade. A lista é ampla, sendo possível citar pelo menos sete tipos específicos desses canais: os conselhos gestores de políticas, as conferências temáticas, as ouvidorias, as audiências públicas, as consultas públicas, as reuniões com grupos de interesse e, por fim, os canais como sítios de internet, as ações pontuais de divulgação de ações governamentais etc. (Quadro 2). Essas interfaces seriam, na visão dos autores, passíveis de classificação em duas subdimensões específicas, tendo por base os prismas por eles apresentados: interfaces coletivizadas e interfaces não coletivizadas. 


\section{Quadro 2 \\ Dimensões de análise estruturantes do conceito de capacidade socioestatal a partir das interfaces socioestatais}

\begin{tabular}{|c|c|c|c|}
\hline Dimensão & Subdimensão & Categoria & Descrição \\
\hline \multirow{6}{*}{$\begin{array}{l}\text { Capacidades } \\
\text { socioestatais }\end{array}$} & \multirow{3}{*}{$\begin{array}{c}\text { Interfaces não } \\
\text { coletivizadas }\end{array}$} & Ouvidoria & $\begin{array}{l}\text { São instâncias dos órgãos governamentais que, através da disponibilização de um } \\
\text { meio específico para contato, geralmente via telefone ou, ainda, e-mail, site ou } \\
\text { redes sociais, recebem reclamações, denúncias e/ou demandas gerais dos } \\
\text { cidadãos. Essas últimas são analisadas e internamente trabalhadas pelos setores } \\
\text { responsáveis, de modo a que os objetivos delineados sejam efetivamente atendidos } \\
\text { (Quintão e Cunha, 2018). }\end{array}$ \\
\hline & & $\begin{array}{l}\text { Reuniões c/ } \\
\text { grupos de } \\
\text { interesse }\end{array}$ & $\begin{array}{l}\text { São canais pelos quais grupos espećíficos da sociedade, como empresários, } \\
\text { sindicalistas, entre outros, negociam diretamente com o governo determinadas } \\
\text { questões que mais lhes interessam. Via de regra, é iniciativa do próprio governo } \\
\text { em resposta à representação e/ou demandas de entidades ou movimentos sociais } \\
\text { com fins de solucionar eventuais e/ou potenciais conflitos (Cardoso Jr., 2014). }\end{array}$ \\
\hline & & Outros & $\begin{array}{l}\text { São canais pelos quais não apenas o governo pode publicizar suas ações, mas } \\
\text { também os cidadãos podem eventualmente expressar suas demandas, reclamos e } \\
\text { opiniões. Esse é o caso, por exemplo, dos sítios de internet e dos telefones que são } \\
\text { disponibilizados para os cidadãos para contato com gestores e/ou administradores } \\
\text { de programas específicos. }\end{array}$ \\
\hline & \multirow{3}{*}{$\begin{array}{l}\text { Interfaces } \\
\text { coletivizadas }\end{array}$} & $\begin{array}{l}\text { Audiência } \\
\text { Pública / } \\
\text { Consulta } \\
\text { Pública }\end{array}$ & $\begin{array}{l}\text { Audiências são encontros públicos presenciais, promovidos pelo governo em torno } \\
\text { de temáticas específicas, com objetivo de discutir aspectos concernentes a } \\
\text { determinada política, sendo aberta a participação a todos os indivíduos interessados } \\
\text { (Fonseca et al., 2013). As consultas são instrumentos semelhantes com a diferença } \\
\text { que sua estruturação não se dá necessariamente de forma presencial, mas através } \\
\text { de ferramentas de votação à distância. }\end{array}$ \\
\hline & & $\begin{array}{l}\text { Conselho } \\
\text { gestor }\end{array}$ & $\begin{array}{l}\text { São instituições constitucionalmente previstas nos três níveis de governo, com } \\
\text { formato híbrido, sendo, em geral, compostas de forma paritária por membros do } \\
\text { governo e membros da sociedade civil, para a discussão de várias questões no } \\
\text { tocante a políticas públicas de diversas áreas e temáticas (Avritzer, 2009; Cunha, } \\
\text { 2011). }\end{array}$ \\
\hline & & $\begin{array}{l}\text { Conferência } \\
\text { temática }\end{array}$ & $\begin{array}{l}\text { São eventos que ocorrem com periodicidade específica, geralmente nos três níveis } \\
\text { de governo, nos quais as principais questões e direcionamentos normativos de } \\
\text { áreas temáticas em políticas públicas são determinados (Progrebinschi, 2010). A } \\
\text { participação é aberta ao público, ainda que, nos níveis estadual e nacional, apenas } \\
\text { delegaados escolhidos tenham poder de voto (Ribeiro et al., 2015). }\end{array}$ \\
\hline
\end{tabular}

Fonte: Pires e Vaz (2014, p. 69).

A primeira subdimensão seria relativa àquelas interfaces supostamente capazes de englobar e impactar, direta ou indiretamente, uma parcela considerável de indivíduos e grupos, bem como dotadas de significativas periodicidade e perenidade no que tange a sua execução. Aqui os autores incluem interfaces como os Conselhos Gestores Setoriais, as Conferências Temáticas, as Audiências Públicas e as Consultas Públicas. A segunda subdimensão estaria relacionada àquelas interfaces detentoras de caráter mais individualizante, com potencial de gerar benefícios e impactar grupos e/ou indivíduos de maneira muito mais pontual e menos difusa/holística. Sua periodicidade seria relativamente menor do que aquela da subdimensão anterior, contando com ocorrências às vezes até mesmo de forma ad hoc. Nela são incluídas as interfaces reunião com grupos de interesse, ouvidorias e outros. 
A capacidade socioestatal estaria ligada ao potencial do Estado de se utilizar desses espaços, garantindo a legitimidade de suas ações, bem como a transparência de seus atos, a depender do tipo de política levada a cabo (Pires e Vaz, 2014). Uma vez institucionalizada essa lógica de atuação como método efetivo de gestão, para além da disposição unitária e/ou singular das capacidades do tipo burocrático, os custos transacionais estariam, cada qual, factualmente minorados, sugere-se, nos seus respectivos potenciais de influenciar e impactar negativamente os processos públicos de tomada de decisão (Coelho e Nobre, 2004; Sintomer, 2010; Avritzer, 2015). Em primeiro lugar, no que concerne ao aspecto da dispersão decisória, o ator estaria preparado, por exemplo, para a negociação com diversos e distintos grupos no âmbito das decisões descentralizadas, já que dotado de instâncias desenhadas e operacionalizadas especificamente para esse fim (Lavalle e Szwako, 2015). Essa preparação tenderia a impactar diretamente os custos advindos do necessário e premente esforço de coordenação e harmonização de interesses e preferências que o Estado deve assumir quando da interação estabelecida entre os seus próprios agentes burocráticos, bem como entre estes e os atores externos. O que ocorre é que, nesse caso, a instrumentalização desse esforço passaria a contar com suporte institucional customizado e desenhado para o tipo e o objetivo de cada interação a ser estabelecida (Avritzer, 2009).

Em segundo lugar, no que tange à centralidade política, os projetos e ações a serem empreendidos tenderiam a sofrer menor grau de ingerência casuística na sua implementação. Esse cerceamento da influência política se daria como função de um conjunto de instâncias decisórias de caráter colegiado estruturadas como base legitimadora efetiva dos processos públicos de tomada de decisão (Lavalle, Voigt e Serafim, 2016). De maneira efetiva, as ordens passariam a necessariamente contar com o aval ou, no mínimo, o escrutínio de instâncias colegiadas instituídas como base para a tomada de decisão, diminuindo os riscos associados à emissão de ordenamentos, despachos, escolhas etc., originados de poucos indivíduos dotados de interesses específicos, mas com poder decisório instituído3 (Santos e Avritzer, 2003; Brasil, 2013). Por fim, em terceiro lugar, temos o caso da entropia burocrática, que seria minimizada pelo contato constante dos agentes e técnicos não apenas com outros atores pertencentes à própria burocracia, mas, também, com indivíduos e grupos externos a esse contexto (Faria, 2017). O estabelecimento desse contato seria relevante para que os técnicos e agentes estatais, especialmente aqueles de médio e alto escalão (tomadores de decisão), estivessem mais aptos a se inteirar de outras perspectivas para o desenho e a gestão de políticas públicas

\footnotetext{
3 Esse foi o caso, por exemplo, do estabelecimento do Sistema Único de Assistência Social, doravante Suas, no país, que contou com o assentamento de instâncias colegiadas que lograram congregar, após quase 20 anos de promulgação da Constituição, uma política de assistência social estruturada, sistematizada e consistente, capaz de perpassar governos e se caracterizar muito mais como uma política de Estado do que como uma política de governo (Jaccoud, 2009; Satyro e Cunha, 2014).
} 
para além daquelas já estabelecidas entre seus próprios grupos de ação 4 (Abers, Serafim e Tatagiba, 2014).

A partir de todo esse processo de potencial mitigação dos custos transacionais, não é difícil perceber que estariam criadas as condições e circunstâncias mais propícias à obtenção de melhorias relativas nos resultados das operações governamentais (Leftwich, 1998; Meirelles, 2010; Santos e Marques, 2015). Em particular, com um menor grau de dispersão decisória, uma intensidade mais baixa de ingerência política e uma perspectiva maior e mais sistematizada de contato entre burocratas, seus pares e atores externos, o grau de previsibilidade dos processos de tomada de decisão, em especial no tocante aos seus resultados, tenderia a aumentar gradativa e acumuladamente, implicando melhor preparação e maior capacidade de resposta do Estado para o enfrentamento das complexidades associadas aos processos de produção, implementação e gestão das políticas públicas (Coles e Hesterly, 1998; Peres, 2007; Fiani, 2011, 2013). Nesse sentido, uma vez admitidas as capacidades socioestatais como fontes prementes e elementos catalisadores desse processo, cabe indagar da validade de se admitir, ato contínuo, não apenas o seu papel como agente fomentador de melhorias nos resultados apresentados pela administração pública, mas também as condições sob as quais tal processo poderia se perfazer e/ou instrumentalizar. Isto é, saber se e sob que condições o desenvolvimento de capacidades socioestatais favorece, de fato, a apresentação de melhores resultados no âmbito da gestão de políticas públicas.

Para lidar com essa questão, duas estratégias analítico-metodológicas serão adotadas. Em primeiro lugar, iremos elaborar dois índices sintéticos com fulcro na operacionalização e instrumentalização analítica de ambas as capacidades, confrontandoos com o nível de resultados apresentados por programas públicos elegidos para investigação. Isso permitirá checar se o desenvolvimento das capacidades ora tratadas, especialmente no caso da socioestatal, favorece efetivamente a apresentação de melhores resultados no âmbito da gestão desses programas. Logo em seguida, faremos um estudo qualitativo de casos selecionados, buscando descobrir sob que condições esse processo se efetiva. Para tanto, iremos cotejar e confrontar programas estruturados sob regimes de alta e baixa capacidades, analisando como se conforma, para cada um deles, a dinâmica de influência das dimensões em análise nos custos transacionais associados à operacionalização de suas respectivas atividades e ações.

\footnotetext{
${ }^{4}$ Efetivamente, esse contato tem sido cada vez mais premente no âmbito da administração pública de uma forma geral e tem gerado impactos sobretudo positivos na forma de execução das políticas setoriais, tal como relatado por Pogrebinschi (2010) e Ribeiro et al. (2015), para o caso da realização das conferências temáticas nacionais; por Almeida e Cunha (2016), para o caso da operação dos Conselhos Gestores de Políticas Públicas; ou, ainda, por Wampler (2008), para o caso das audiências e consultas públicas para definições e alocações orçamentárias especialmente em nível municipal.
} 


\section{Capacidades e resultados efetivos em políticas públicas}

A execução da primeira estratégia metodológica demanda inicialmente a definição, para além dos aspectos meramente conceituais que servem de base às capacidades ora trabalhadas, dos instrumentos operacionais e dos parâmetros capazes de informar em que sentido elas variam e com qual intensidade isso ocorre. O desafio aqui, note-se, perpassa a definição teórica dessas capacidades e exige que se traga à baila medidas efetivas para sua concretização em termos de escala e atribuição de valores.

Nesse sentido, vale dizer que tradicionalmente as pesquisas e estudos empíricos empreendidos nas ciências sociais se organizam tendo como ponto de partida a elaboração de indicadores associados à operacionalização dos conceitos eventualmente estudados, para, só então, rastrear as variáveis e, principalmente, as bases de dados capazes de disponibilizar as informações necessárias e requeridas para sua efetiva estruturação (Yin, 2001). Essa estratégia clássica de atuação não raramente redunda em frustrações patentes aos pesquisadores que a utilizam, ao descobrirem que, embora dotados de ótimos indicadores, não conseguem encontrar fontes de dados confiáveis e/ou mesmo válidas para sua compilação (Jannuzzi, 2002). Diferentemente dessa rota clássica, este artigo toma por ponto de partida a busca de bases de dados confiáveis e consistentes compostas por informações capazes de referendar as definições teóricas dos conceitos ora trabalhados, para, só então, partir para a elaboração de indicadores e sua operacionalização efetiva.

Baseados nisso, recorremos, inicialmente, a três bancos de dados e informações tendo por referência as temáticas aludidas pelas subdimensões associadas às capacidades burocrática e socioestatal, tal como definidas na seção analítica anterior (Quadros 1 e 2). Em primeiro lugar, no que concerne especificamente às capacidades burocráticas, elegemos o banco de dados de informações de servidores federais, disponibilizado pela Controladoria-Geral da União, bem como o banco de dados de filiações a partidos políticos, disponibilizado pelo Tribunal Superior Eleitoral. Ambos contam com informações e dados pertinentes às temáticas referenciadas pelas subdimensões profissionalização e autonomia, que são as componentes da dimensão em pauta, concretizadas na escolha de algumas variáveis de especial interesse para o artigo (Quadro 3). No caso do primeiro banco, de servidores federais, a unidade de análise é o indivíduo funcionário público, e, para o segundo banco, de filiações partidárias, a unidade de análise é o indivíduo que é ou já foi filiado a algum partido político. 


\section{Quadro 3}

Bancos de dados utilizados no trabalho, segundo origem, unidade de análise, variáveis de interesse e período disponível

\begin{tabular}{|c|c|c|c|c|c|c|}
\hline Dimensão & Subdimensão & $\begin{array}{l}\text { Banco de } \\
\text { dados }\end{array}$ & Origem & $\begin{array}{c}\text { Unidade } \\
\text { de análise }\end{array}$ & Variáveis de interesse & Período \\
\hline \multirow[t]{2}{*}{$\begin{array}{l}\text { Capacidades } \\
\text { burocráticas }\end{array}$} & Profissionalização & $\begin{array}{l}\text { Servidores } \\
\text { públicos } \\
\text { federais }\end{array}$ & $\begin{array}{l}\text { Controladoria- } \\
\text { Geral da União }\end{array}$ & $\begin{array}{l}\text { Indivíduo - } \\
\text { servidores } \\
\text { públicos }\end{array}$ & $\begin{array}{l}\text { Nome, CPF, Siape, se é efetivo ou } \\
\text { não, carreira a que pertence, bem } \\
\text { como sua temática, órgão de } \\
\text { origem, órgão de exercício, salário, } \\
\text { tempo de exercício em cada órgão, } \\
\text { se ocupa cargo comissionado e } \\
\text { tipo/grau de cargo comissionado } \\
\text { ocupado. }\end{array}$ & $\begin{array}{l}\text { Todos } \\
\text { os anos }\end{array}$ \\
\hline & Autonomia & $\begin{array}{l}\text { Filiações } \\
\text { partidárias }\end{array}$ & $\begin{array}{l}\text { Tribunal } \\
\text { Superior } \\
\text { Eleitoral }\end{array}$ & $\begin{array}{l}\text { Indivíduo - } \\
\text { filiados a } \\
\text { partidos } \\
\text { políticos } \\
\end{array}$ & $\begin{array}{l}\text { Nome, CPF, data da filiação e data } \\
\text { da desfiliação (se for o caso). }\end{array}$ & $\begin{array}{l}\text { Todos } \\
\text { os anos }\end{array}$ \\
\hline \multirow{2}{*}{$\begin{array}{l}\text { Capacidades } \\
\text { socioestatais }\end{array}$} & $\begin{array}{l}\text { Interfaces não } \\
\text { coletivizadas }\end{array}$ & \multirow{2}{*}{$\begin{array}{l}\text { SIGPlan - } \\
\text { Sistema de } \\
\text { Informações } \\
\text { Gerenciais e de } \\
\text { Planejamento }\end{array}$} & \multirow{2}{*}{$\begin{array}{l}\text { Ministério do } \\
\text { Planejamento, } \\
\text { Orçamento e } \\
\text { Gestão }\end{array}$} & \multirow{2}{*}{$\begin{array}{l}\text { Programas - } \\
\text { programas } \\
\text { de políticas } \\
\text { públicas }\end{array}$} & \multirow{2}{*}{$\begin{array}{l}\text { Órgão executor, se já recorreu a } \\
\text { alguma interface socioestatal, tipo } \\
\text { da interface, quantidade de vezes } \\
\text { em que recorreu e ano da } \\
\text { ocorrência. }\end{array}$} & \multirow{2}{*}{$\begin{array}{l}\text { De } 2004 \\
\text { a } 2009\end{array}$} \\
\hline & $\begin{array}{l}\text { Interfaces } \\
\text { coletivizadas }\end{array}$ & & & & & \\
\hline
\end{tabular}

Fonte: Elaboração própria.

Para o tratamento e análise das capacidades socioestatais, elegemos o banco de dados do SIGPlan, Sistema de Informações Gerenciais e de Planejamento, criado em 2000 pelo Ministério do Planejamento, Orçamento e Gestão, com o objetivo de auxiliar na elaboração e acompanhamento do PPA do governo federal, por meio da centralização e sistematização computacional de informações quantitativas e qualitativas relativas à implementação dos programas e ações governamentais (MPOG, 2014). Sua unidade de análise, diferentemente dos dois bancos anteriores, calcados no indivíduo, é o programa desenvolvido por órgão da administração direta do poder Executivo federal, sendo que, para as variáveis de interesse elegidas nesse caso, o período disponível variou de 2004 a 2009 (Quadro 3).

Essas três bases de dados - banco de servidores federais, banco de filiações partidárias e SIGPlan - foram utilizadas em conjunto nessa investigação, de maneira a permitir a elaboração de indicadores que efetivamente retratassem as dimensões aqui trabalhadas. Realizou-se, para tanto, um trabalho de integração desses bancos calcado na metodologia de matching pairs do tipo determinístico (Vaz et al., 2014). O procedimento é baseado na geração de chaves de ligação que sejam ao mesmo tempo únicas para cada caso tratado e que estejam presentes em todas as bases analisadas, de forma a possibilitar um processo de pareamento exclusivo entre cada unidade ( $\mathrm{Li}$, Fong e Lu, 2007). Dessa forma, é possível encontrar a mesma unidade dentre as bases trabalhadas e agregar a ela todas as informações almejadas, segundo o menor nível de agregação disponível no 
conjunto avaliado (Wooldridge, 2010). Foram necessárias duas etapas para geração de uma base de dados passível de conter as informações requeridas a este artigo.

Em primeiro lugar, na etapa 1, os bancos de dados de servidores públicos federais e de filiações partidárias foram integrados segundo o procedimento de matching através de um algoritmo determinístico desenhado para estabelecer conexão entre as variáveis nome e CPF de cada indivíduo presente nas amostras - já que ambas as variáveis se mostraram disponíveis nos dois bancos. As informações de filiação partidária foram, nesse processo, incorporadas ao banco de servidores, sendo associadas a cada indivíduo dotado do mesmo nome e CPF. Ao cabo, foi composta uma base na qual, para cada funcionário público, dispunha-se, para além das informações originais da base de servidores (como carreira, órgão de exercício etc.), de variáveis de interesse afetas à matéria de filiação partidária (como data de filiação, partido político etc.) - isto é, ao cabo, o banco foi composto com todas as variáveis relativas às capacidades burocráticas dispostas no Quadro 3.

A segunda etapa do processo consistiu na estruturação de uma base de informações integradas pelo banco de dados compilado na etapa 1 e o banco de dados do SIGPlan. Ocorre que, como já referido, o SIGPlan tem uma unidade de análise diferente daquela presente nesse banco resultante da etapa 1 , sendo indivíduos, para este último, e programas desenvolvidos por órgãos do Executivo federal, para o primeiro. Assim, foi preciso, previamente a essa integração, equalizar ou harmonizar essas bases de dados no sentido de contar com unidades de análise e variáveis em comum que servissem de pontos de conexão efetiva entre ambas. Isso foi feito a partir de um processo intermediário de agregação de informações individuais (Wooldridge, 2010) no banco resultante da etapa 1 , adotando por critério de associação a variável órgão de exercício dos indivíduos. A escolha dessa variável se deu por ser ela, no âmbito desse banco, a que mais se aproximava do nível de agregação do SIGPlan, já que não contava com uma variável relacionada especificamente a programas - que, pelo exposto em relação às características do SIGPlan, seria a variável que geraria o nível de agregação ideal.

O resultado desse processo de agregação foi a criação de uma base de dados intermediária, com a temática de servidores e filiações partidárias, cuja unidade de análise redundou não mais nos indivíduos/funcionários públicos, mas sim nos órgãos da administração direta do poder Executivo nos quais esses indivíduos/funcionários públicos exerciam suas atividades para cada ano considerado (Quadro 4): 


\section{Quadro 4 \\ Critérios e novas variáveis criadas no banco intermediário de servidores e filiações partidárias}

\begin{tabular}{|c|c|c|c|}
\hline $\begin{array}{l}\text { Base de dados } \\
\text { intermediária }\end{array}$ & $\begin{array}{c}\text { Unidade de } \\
\text { análise }\end{array}$ & $\begin{array}{c}\text { Variável de interesse } \\
\text { original }\end{array}$ & Nova variável de interesse \\
\hline \multirow{3}{*}{$\begin{array}{l}\text { Base integrada } \\
\text { servidores e } \\
\quad \text { filiações }\end{array}$} & \multirow{3}{*}{$\begin{array}{c}\text { Indivíduos } \\
\text { funcionários dos } \\
\text { órgãos da } \\
\text { administração } \\
\text { direta do poder } \\
\text { Executivo federal }\end{array}$} & $\begin{array}{l}\text { Se é efetivo ou não } \\
\text { (efetividade na função pública) }\end{array}$ & $\begin{array}{l}\text { Quantidade de indivíduos efetivos em exercício } \\
\text { no órgão }\end{array}$ \\
\hline & & Carreira a que pertence & $\begin{array}{l}\text { Quantidade de indivíduos em exercício no órgão } \\
\text { pertencentes a carreiras divididas segundo } \\
\text { temáticas específicas }\end{array}$ \\
\hline & & $\begin{array}{c}\text { Órgão de exercício e órgão de } \\
\text { origem }\end{array}$ & $\begin{array}{l}\text { Quantidade de indivíduos em exercício no órgão } \\
\text { que foram cedidos temporariamente }\end{array}$ \\
\hline \multirow{4}{*}{$\begin{array}{l}\text { Base integrada e } \\
\text { agregada } \\
\text { servidores e } \\
\text { filiações } \\
\text { (BD Intermediário) }\end{array}$} & \multirow{4}{*}{$\begin{array}{c}\text { Órgãos da } \\
\text { administração } \\
\text { direta do poder } \\
\text { Executivo federal }\end{array}$} & Último salário & $\begin{array}{l}\text { Salário médio dos indivíduos em exercício no } \\
\text { órgão }\end{array}$ \\
\hline & & Tempo de exercício no órgão & $\begin{array}{l}\text { Tempo médio de exercício dos indivíduos no } \\
\text { órgão }\end{array}$ \\
\hline & & $\begin{array}{c}\text { Se ocupa cargo comissionado } \\
\text { e tipo/grau }\end{array}$ & $\begin{array}{l}\text { Quantidade de indivíduos ocupantes de cargos } \\
\text { comissionados }\end{array}$ \\
\hline & & Data de filiação e desfiliação & $\begin{array}{l}\text { Quantidade de indivíduos em exercício no órgão } \\
\text { que são filiados a partidos políticos }\end{array}$ \\
\hline
\end{tabular}

Fonte: Elaboração própria.

A partir da criação desse banco de dados intermediário agregado, foi possível, afinal, realizar a estruturação da base de informações que, ao cabo, serviu como pilar deste artigo. A base intermediária foi integrada ao banco de dados do SIGPlan, tendo por critério de adjeção duas variáveis: o órgão da administração direta do poder Executivo e o ano ambos presentes nos dois bancos. Como no banco do SIGPlan a unidade de análise efetiva concerne aos programas e não aos órgãos, as informações atinentes a cada um desses órgãos foram replicadas para todos aqueles programas, ponderando-se por sua esfera de pertencimento (isto é, pelo órgão de pertencimento) e, naturalmente, pelas variações de ano (Figura 1):

\footnotetext{
${ }^{5}$ As temáticas são aquelas apontadas por Pires e Vaz (2014), seguindo o mesmo critério dos autores para a classificação: Proteção e promoção social, com carreiras ligadas às políticas sociais típicas (educação, saúde e assistência) e serviços, projetos e ações para promoção e garantia de direitos, proteção de minorias etc.; Desenvolvimento econômico, com carreiras que desenvolvem ações de apoio, fomento, regulação, financiamento, entre outras, voltadas para a promoção do desenvolvimento econômico, ao setor produtivo, à organização do mercado e ao estímulo ao crescimento econômico; Infraestrutura, com carreiras voltadas para o desenvolvimento de infraestruturas nas diversas áreas - seja logística e infraestrutura produtiva, estrutura e qualidade dos serviços públicos, infraestrutura urbana e urbanização, transporte, energia, telecomunicações etc.; Meio ambiente e recursos naturais, com carreiras ligadas a iniciativas de prevenção e conservação de recursos naturais.
} 
Figura 1

Dinâmica e perfil de integração final das bases de dados utilizadas neste artigo

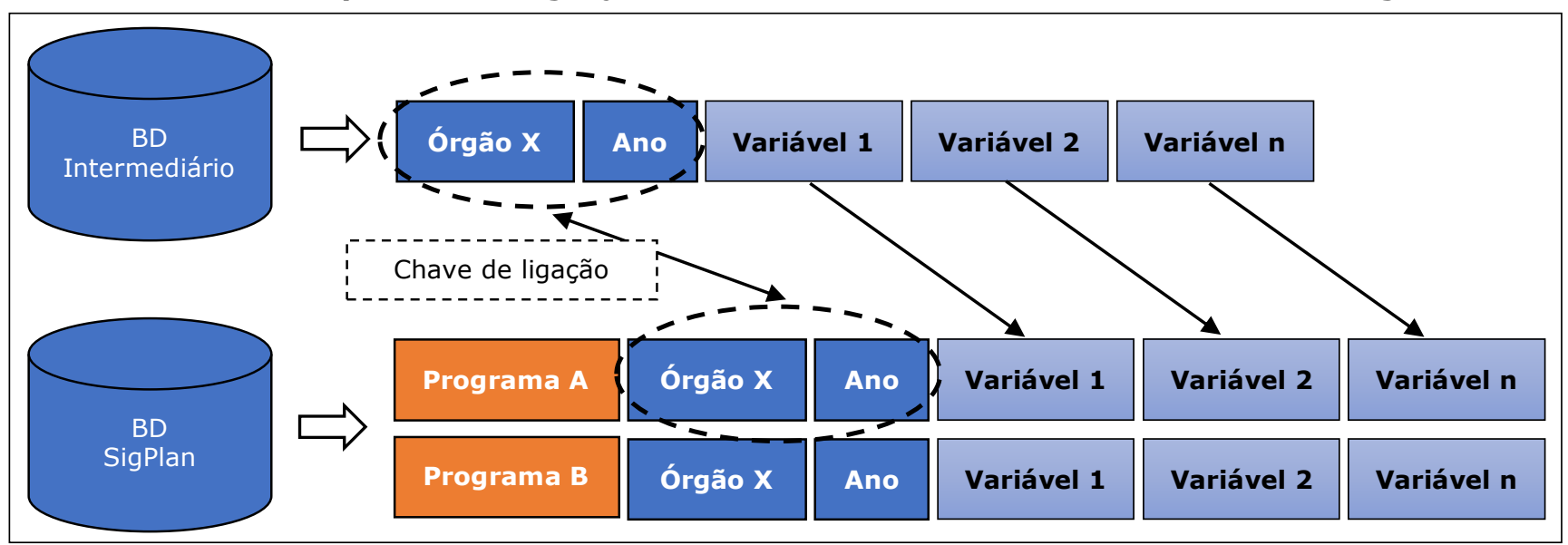

Fonte: Elaboração própria.

Isso quer dizer que, tomando por base as variáveis elencadas para as capacidades burocráticas no banco de dados final utilizado neste artigo, não é possível estabelecer uma associação direta entre essas capacidades e singularidades e/ou especificidades de cada programa, mas, sim, entre aquelas de cada órgão que o executa e por ele se responsabiliza. Em outras palavras, as capacidades burocráticas, tal como mensuradas aqui, não são estratificáveis por programas, mas sim por órgãos. A implicação mais direta disso para a investigação é que as capacidades destes últimos são tomadas como proxy para mensuração das capacidades dos primeiros ${ }^{6}$.

A base de dados final foi composta por 1.969 casos, relativos a 492 programas pertencentes a 48 órgãos da administração direta do poder Executivo federal brasileiro. Como cada programa pode se repetir em diferentes anos no período considerado - de 2004 a 2009 -, desde que ativo no ano específico analisado (sendo que, naturalmente, as informações que lhe subjazem tendem a sofrer variações), a quantidade total de programas investigados é, factualmente, menor do que a quantidade total de casos disponibilizados. Assim, o que estamos considerando como caso, neste artigo, concerne às informações anuais dos programas desenvolvidos pelos órgãos aludidos, seja em relação

6 Pires e Gomide (2016), ao discutirem os arranjos institucionais mais propícios à implementação de políticas públicas, por exemplo, abordam a questão ao argumentarem que as capacidades presentes nos diferentes programas são variáveis e distintas entre si, sendo que seria justamente esse o fator que propiciaria a obtenção de resultados diferenciados no âmbito da execução de cada uma delas. Ocorre que o tipo de capacidade que os autores estão tratando ao lidarem com o âmbito da técnica burocrática, mais especificamente com a capacidade que denominam de técnico-administrativa (que seria aquela ligada diretamente à gestão dos programas), é, na verdade, o resultado de arranjos institucionais que envolvem a "combinação de organizações profissionalizadas com mecanismos efetivos de coordenação intra e intergovernamentais" (p. 121). A capacidade técnico-administrativa sofreria variação de acordo com o grau e o tipo de combinação estabelecida entre esses fatores, organizações profissionalizadas e mecanismos de coordenação, mas não pela criação efetiva de cada um deles no âmbito dos processos de gestão e implementação dos programas. 
às suas capacidades burocráticas (cujas variáveis descritoras são aquelas novas variáveis constantes do Quadro 4), seja em relação às suas capacidades socioestatais (cujas variáveis descritoras são aquelas constantes do Quadro 3).

A partir das informações ao cabo compiladas, foi estruturada uma cesta de indicadores com fulcro nas categorias e variáveis que instrumentalizam os conceitos das capacidades tal como postuladas neste artigo 7 (Tabela 1). Procedeu-se, com isso, à análise da distribuição dos dados e informações de interesse entre os indicadores estruturados (Tabela 1). Foi possível observar, para o caso da dimensão de capacidades burocráticas, por exemplo, que o primeiro indicador, relativo à proporção de técnicos envolvidos no órgão que pertencem a alguma carreira pública de temática específica de seu trabalho, aumentou, no geral, de aproximadamente $11,9 \%$ para $22,4 \%$. Isso quer dizer que, dentre os casos considerados para análise, foi cada vez mais frequente, ao longo do tempo, a presença de técnicos concursados em carreiras da própria temática do órgão executor do programa, contribuindo para a expertise e a menor rotatividade no desenvolvimento dos trabalhos. Já o tempo médio de permanência dos técnicos era de, por exemplo, pouco mais de 5 anos em 2004 e subiu para mais de 11 anos em 2009. Isso demonstra que a burocracia foi não apenas alocando técnicos ligados à própria temática nos seus órgãos, como também que esses técnicos permaneceram nas suas respectivas funções, tendo possibilidade de efetivamente desenvolverem trabalho de longo prazo e com, sugere-se, maior consistência.

\footnotetext{
7 Assim, por exemplo, para a operacionalização da categoria mandato principal da carreira, componente da subdimensão Profissionalização (das capacidades burocráticas), foi calculado tendo por base a definição que Ihe foi atribuída no Quadro 1, o indicador proporção de técnicos do órgão executor do programa que pertencem a alguma carreira pública que seja especificamente da área temática do programa - que é resultante da divisão do total de servidores do órgão executor do programa que pertencem a alguma carreira pública que seja especificamente da área temática do programa pelo total de servidores do órgão executor do programa. Com isso, podemos averiguar a proporção da força de trabalho empenhada no desenvolvimento de determinado programa que, sugere-se, carrega maior capacidade para o desempenho da atividade, tendo por função não apenas o seu prévio envolvimento na temática, mas também sua formação destinada especificamente para isso.
} 
Tabela 1

Matriz analítica e percentuais para classificação dos programas desenvolvidos pelo Estado sob a égide de suas capacidades

\begin{tabular}{|c|c|c|c|c|c|c|c|}
\hline Dimensão & Subdimensão & Categoria & Indicador & Unid. & 2004 & 2009 & Peso \\
\hline \multirow{7}{*}{$\begin{array}{l}\text { Capacidades } \\
\text { burocráticas }\end{array}$} & \multirow{5}{*}{ Profissionalização } & $\begin{array}{l}\text { Mandato } \\
\text { principal da } \\
\text { carreira }\end{array}$ & $\begin{array}{l}\text { Proporção de técnicos do órgão executor do } \\
\text { programa que pertencem a alguma carreira } \\
\text { pública que seja especificamente da área } \\
\text { temática do programa }\end{array}$ & $\%$ & 11,86 & 22,36 & 0,100 \\
\hline & & $\begin{array}{l}\text { Mandato de } \\
\text { especialista }\end{array}$ & $\begin{array}{l}\text { Proporção de técnicos do órgão executor do } \\
\text { programa que, embora não pertençam à } \\
\text { carreira específica do próprio órgão, pertencem } \\
\text { a alguma carreira especializada na temática do } \\
\text { programa }\end{array}$ & $\%$ & 67,16 & 62,81 & 0,100 \\
\hline & & $\begin{array}{l}\text { Longevidade } \\
\text { no serviço } \\
\text { público }\end{array}$ & $\begin{array}{l}\text { Tempo em que os técnicos do órgão executor } \\
\text { do programa têm trabalhado não só no serviço } \\
\text { público, mas especificamente na temática do } \\
\text { programa }\end{array}$ & Anos & 5,1 & 11,9 & 0,100 \\
\hline & & $\begin{array}{l}\text { Servidores } \\
\text { requisitados }\end{array}$ & $\begin{array}{l}\text { Proporção de técnicos do órgão executor do } \\
\text { programa que são requisitados de outras } \\
\text { agências }\end{array}$ & $\%$ & 16,5 & 16 & $-0,100$ \\
\hline & & $\begin{array}{c}\text { Salários } \\
\text { competitivos }\end{array}$ & $\begin{array}{l}\text { Remuneração média dos técnicos do órgão } \\
\text { executor do programa }\end{array}$ & $\mathrm{R} \$$ & 5.410 & 6.928 & 0,100 \\
\hline & \multirow[t]{2}{*}{ Autonomia } & DAS políticos & $\begin{array}{l}\text { Proporção de técnicos do órgão executor do } \\
\text { programa que são ocupantes de cargos DAS, de } \\
\text { livre nomeação, e que são também filiados a } \\
\text { partidos políticos }\end{array}$ & $\%$ & 37,9 & 39,1 & $-0,250$ \\
\hline & & $\begin{array}{l}\text { Técnicos } \\
\text { políticos }\end{array}$ & $\begin{array}{l}\text { Proporção de técnicos do órgão executor do } \\
\text { programa que são filiados a partidos políticos }\end{array}$ & $\%$ & 38,4 & 39,9 & $-0,250$ \\
\hline \multirow{7}{*}{$\begin{array}{l}\text { Capacidades } \\
\text { socioestatais }\end{array}$} & \multirow{3}{*}{$\begin{array}{l}\text { Interfaces não } \\
\text { coletivizadas }\end{array}$} & Ouvidoria & Proporção de programas que utilizam ouvidoria & $\%$ & 26,0 & 41,1 & 0,100 \\
\hline & & $\begin{array}{l}\text { Reuniões } \\
\text { grupos } \\
\text { interesse }\end{array}$ & $\begin{array}{l}\text { Proporção de programas que realizam reunião } \\
\text { com grupos de interesse }\end{array}$ & $\%$ & 31,2 & 53,9 & 0,100 \\
\hline & & $\begin{array}{l}\text { Website/ } \\
\text { Telefone } \\
\text { gratuito }\end{array}$ & $\begin{array}{l}\text { Proporção de programas que disponibilizam } \\
\text { website ou telefone gratuito para contato }\end{array}$ & $\%$ & 20,7 & 24,5 & 0,100 \\
\hline & \multirow{4}{*}{$\begin{array}{l}\text { Interfaces } \\
\text { coletivizadas }\end{array}$} & $\begin{array}{l}\text { Audiência } \\
\text { Pública }\end{array}$ & $\begin{array}{l}\text { Proporção de programas que realizaram pelo } \\
\text { menos uma audiência pública }\end{array}$ & $\%$ & 8,3 & 27,8 & 0,175 \\
\hline & & $\begin{array}{l}\text { Consulta } \\
\text { Pública }\end{array}$ & $\begin{array}{l}\text { Proporção de programas que realizaram pelo } \\
\text { menos uma consulta pública }\end{array}$ & $\%$ & 7,7 & 17,4 & 0,175 \\
\hline & & $\begin{array}{l}\text { Conselho } \\
\text { Gestor }\end{array}$ & $\begin{array}{|lcc|}\begin{array}{l}\text { Proporção de programas submetidos a } \\
\text { conselhos gestores pelo menos uma vez }\end{array} & \\
\end{array}$ & $\%$ & 19,1 & 32,0 & 0,175 \\
\hline & & $\begin{array}{l}\text { Conferência } \\
\text { Temática }\end{array}$ & \begin{tabular}{|lll}
$\begin{array}{l}\text { Proporção de programas submetidos a } \\
\text { conferências temáticas pelo menos uma vez }\end{array}$ \\
\end{tabular} & $\%$ & 5,0 & 17,4 & 0,175 \\
\hline
\end{tabular}

Fonte: Servidores Federais CGU; Filiações Partidárias TSE; SIGPlan MPOG.

Para além das capacidades burocráticas, importa notar que o governo também desenvolveu importantes avanços em termos de capacidades socioestatais. A proporção de casos cujos processos decisórios foram submetidos ao debate em Conselhos Gestores de Políticas Públicas, por exemplo, passou de 19\% em 2004 para 32\% em 2009, um aumento de 13 pontos percentuais. Nessa mesma linha, é relevante notar que as audiências e consultas públicas também foram cada vez mais adotadas: consideradas em 
conjunto, sua média de adoção em 2004 girava em torno de $8 \%$ dos casos e, já em 2009, essa média subiu para praticamente $23 \%$. Na média global, o percentual de casos que se utilizavam de interfaces socioestatais no período passou de 16,9\% em 2004 para 30,6\% em 2009, o que mostra que, seja pela força da lei, seja pela própria disponibilidade dos gestores, não é desprezível a abertura cada vez maior à discussão e ao escrutínio público a que os programas foram se propondo.

\section{Tendências e averiguação de capacidades}

Em conjunto, de forma geral, não é difícil perceber a existência de certa tendência no rol de dados apresentados. Entre 2004 e 2009, parece que o governo foi capaz de melhorar suas capacidades burocráticas, bem como pôde garantir maior transparência e contato com a sociedade no âmbito de sua gestão, através da melhoria, também, de suas capacidades socioestatais. Como forma de melhor compreender esse movimento, buscouse elaborar dois índices sintéticos (Yin, 2001), cada qual relacionado a uma das capacidades, tendo por base as dimensões e subdimensões que lhes servem de composição. A ideia de estruturação desse instrumento está ancorada na possibilidade de avaliação e diagnóstico imediato de um conjunto de elementos que, de outra sorte, exigiriam recursos e maiores investigações para serem analisados (Brady, 2003; Jannuzzi, 2016).

Segundo Feres e Villatoro (2013), a metodologia-base para a computação de índices contemplaria pelo menos três aspectos: 1) seleção das dimensões; 2) definição de padrões mínimos para as dimensões; e 3) agregação das dimensões através de critérios de pontuação elegidos pelo pesquisador. Aplicando-a para as capacidades burocráticas e socioestatais, cada caso foi avaliado num sistema de pontuação de acordo com os valores que apresentaram, para os indicadores componentes das subdimensões de análise aqui investigadas (Tabela 1). A dimensão de capacidades burocráticas, por exemplo, recebeu peso total igual a 1 , que foi distribuído igualmente entre suas duas subdimensões, profissionalização $(0,5)$ e autonomia $(0,5)$, e, ao cabo, para cada categoria, foi redistribuído igualmente entre seus respectivos indicadores de composição. Para as capacidades socioestatais, a lógica foi a mesma: o peso 1 foi distribuído entre suas subdimensões, interfaces coletivizadas $(0,5)$ e interfaces não coletivizadas $(0,5)$, e, então, foi redistribuído igualmente entre suas respectivas categorias/indicadores.

O valor final efetivo de cada índice, relativo a cada dimensão de análise, foi dado por um processo de duas vias (Jannuzzi, 2002; Yin, 2001). Primeiro, pelo somatório do resultado da multiplicação direta dos valores dos indicadores pelos seus respectivos ponderadores. Esse processo se mostrou relativamente simples porque envolveu, para cada caso, a multiplicação direta do valor singular de cada indicador pelo seu respectivo ponderador, fazendo-se, logo em seguida, a soma de todos os montantes encontrados (Feres e Villatoro, 2013). Segundo, temos o processo de parametrização da pontuação 
encontrada em cada caso, adotando por referência uma escala arbitrária que varia de 0 a 1 (Wooldridge, 2010). Esse processo exigiu que fizéssemos escolhas um pouco mais elaboradas, já que a parametrização é uma técnica na qual atribuímos, na escala considerada, um montante específico para os valores de pontuação dos indicadores que foram previamente calculados (Yin, 2001). A escolha mais importante nesse processo concerne, sem dúvida, à escolha do valor de pontuação a ser associado ao valor máximo da escala, estabelecendo-se um padrão para avaliação dos casos através do cálculo do score que seria atingido por um caso a ser considerado como tipo ideal.

Para isso, adotamos dois procedimentos específicos, ambos focados na diminuição do nível de arbitrariedade que está naturalmente envolvido nesse tipo de processo (Jannuzzi, 2016). Primeiro, para o caso dos indicadores cujas métricas se baseiam em valores percentuais, consideramos que o valor atingido por um caso tipo ideal seria o de $100 \%$. Assim, por exemplo, se considerarmos o indicador proporção de técnicos do órgão executor do programa que pertencem a alguma carreira pública que seja especificamente da área temática do programa, consideramos que o caso tipo ideal teria valor de pontuação de $100 \%$ dos seus técnicos nessa condição. Segundo, para os indicadores relativos às categorias longevidade no serviço público e salários competitivos, cujas métricas se dão, respectivamente, em anos e em Reais $(R \$)$, fizemos o cálculo da soma dos valores encontrados nos anos extremos da amostra, 2004 e 2009. Assim, para o primeiro caso, encontramos o valor de 17 anos e, para o segundo caso, encontramos o valor de R\$ $12.338,00$ - nesse último caso, ao avaliarmos os anos anteriores a 2009, fizemos a devida ponderação inflacionária através do índice INPC - Índice de Preços ao Consumidor Final (IBGE, 2018), ajustando os preços para cada ano considerado.

A partir de todo esse processo de cálculo dos índices e realizando sua estratificação por ano da amostra, notamos claramente tendência de alta efetiva para ambas as dimensões consideradas (Gráfico 1). No caso do índice de capacidade burocrática, ele parte de um patamar de 0,42 em 2004 para um patamar de 0,56 em 2009, o que confirma as suposições de relativa melhoria na gestão burocrática no período considerado. Já no caso das capacidades socioestatais, nota-se maior variabilidade ao longo do tempo, embora ainda também se perceba tendência de alta. O índice parte de um patamar de 0,28 em 2004 e chega em 2009 a 0,3. Todavia, em 2006, por exemplo, ele atinge um pico de 0,38. Existem diversos fatores que podem explicar essa variação, mas, talvez, o mais importante seja o fato de que muitas das interfaces socioestatais adotadas pelos órgãos não têm caráter compulsório e/ou mesmo permanente, dependendo basicamente da vontade do gestor para sua adoção. 
Gráfico 1

Média anual dos índices de capacidades burocráticas - Brasil, de 2004 a 2009

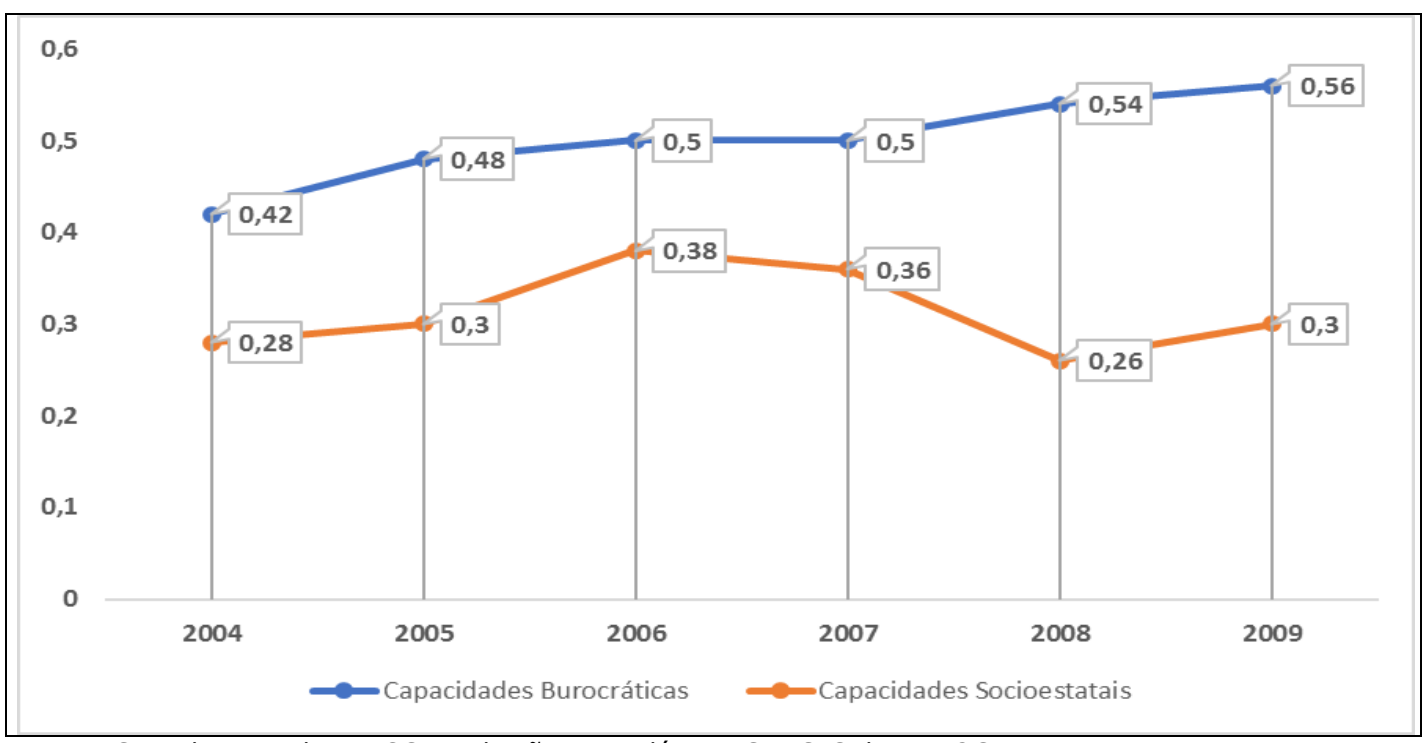

Fonte: Servidores Federais CGU; Filiações Partidárias TSE; SIGPlan MPOG.

Capacidades e influência nos resultados de políticas públicas

Essas diferenças observadas nas médias anuais dos índices nos fornecem dicas de que, na gestão efetiva dos programas, parece existir uma certa complementaridade entre as capacidades, embora o desenvolvimento de cada qual se dê em intensidades e ritmos diferenciados. O que importa investigar, nessa linha, são as implicações práticas dessas diferenças no que tange aos resultados obtidos em cada programa. Para tanto, elegemos uma variável constante originalmente do banco de dados do SIGPlan na qual os gestores devem informar o percentual de resultados obtidos por aqueles empreendimentos sob sua responsabilidade, tendo por referência os resultados previstos inicialmente para cada ano de atividade do projeto. Daremos a essa variável o nome de resultados alcançados. A cada categoria dessa variável (sendo: acima de $100 \%$ do previsto; de $80 \%$ a $100 \%$ do previsto; de $40 \%$ a $79 \%$ do previsto; e abaixo de $40 \%$ do previsto), calculamos a média de pontuação dos índices de capacidades burocrática e socioestatal, bem como a média geral, considerando os dados e informações constantes de toda a amostra, conforme Tabela 2: 
Tabela 2

Média dos índices de capacidades burocrática e socioestatal, segundo níveis de resultado alcançados pelos programas desenvolvidos pelo governo federal Brasil, 2004 a 2009

\begin{tabular}{|l|c|c|c|}
\hline \multirow{2}{*}{ Resultado alcançado } & \multicolumn{3}{|c|}{ Capacidade média } \\
\cline { 2 - 4 } & Burocrática & Socioestatal & Geral \\
\hline Acima de $100 \%$ do previsto & 0,62 & 0,42 & 0,52 \\
\hline De $80 \%$ a $100 \%$ do previsto & 0,54 & 0,34 & 0,44 \\
\hline De $40 \%$ a $79 \%$ do previsto & 0,5 & 0,32 & 0,40 \\
\hline Abaixo de $40 \%$ do previsto & 0,48 & 0,3 & 0,39 \\
\hline
\end{tabular}

Fonte: Servidores Federais CGU; Filiações Partidárias TSE; SIGPlan MPOG.

Observamos, a partir desse procedimento, que as médias dos programas que atingiram resultados melhores são relativamente maiores do que aquelas dos programas que atingiram resultados piores. E isso vale para ambas as dimensões de capacidades. Quando consideramos, por exemplo, os casos que, no período tratado, alcançaram mais de $100 \%$ dos resultados previstos, notamos que a média do índice de capacidade burocrática foi de 0,62 e a média do índice de capacidade socioestatal foi de 0,42 - sendo a média geral de 0,52. Já quando consideramos o lado oposto, isto é, casos cujos resultados ficaram abaixo de $40 \%$ das expectativas e previsões dos gestores, tanto a média de capacidade burocrática quanto a média de capacidade socioestatal caem, respectivamente, para 0,48 e 0,3 - e a média geral cai para 0,39. Parece, assim, que o alcance de bons resultados em gestão de políticas no governo pode estar, de fato, relacionado à melhoria tanto da burocracia quanto da capacidade socioestatal do gestor. $\mathrm{E}$ o fato de, nesse caso, ambos os índices variarem conjuntamente e no mesmo sentido sugere fortemente que o desenvolvimento de ambas as capacidades pode se dar de maneira conjunta. Movimento que pode, a seu turno, determinar as tendências de longo prazo para a gestão das políticas públicas, pois indica que sua utilização de maneira conjunta pode incrementar o potencial de alcance de melhores resultados na gestão dos programas.

Com base nessa constatação, buscou-se investigar mais profundamente essa relação a partir da predição da probabilidade média de dado programa público de apresentar resultados satisfatórios a partir de suas características em termos de capacidades burocrática e socioestatal. Para tanto, foi construído um modelo preditivo que contou com características específicas em sua composição. Em primeiro lugar, a variável resposta, ou dependente, foi considerada como sendo a mesma utilizada acima, resultados alcançados. Contudo, ela contou com uma diferença importante na sua caracterização: suas categorias foram agregadas em apenas dois níveis, programas que foram capazes de atingir pelo menos $80 \%$ dos resultados originalmente previstos e programas que não foram capazes de fazer tal movimento. Em segundo lugar, as variáveis independentes foram estruturadas tendo por base os valores de quartis dos índices associados às subdimensões 
específicas de cada capacidade engendrada - sendo corpo técnico e autonomia, para o caso da capacidade burocrática, e interfaces não coletivizadas e interfaces coletivizadas, para o caso da capacidade socioestatal. O primeiro quartil de cada subdimensão foi elegido para servir como referência na interpretação final das informações computadas (Hair et al., 2009).

Em face do caráter binário da variável dependente, o modelo de regressão escolhido foi o binário logístico, apropriado para situações em que a variável dependente tem essa natureza (Wooldridge, 2010). A regressão logística é uma técnica estatística que tem como objetivo produzir, a partir de um conjunto de observações, um modelo que permita a predição de valores tomados por uma variável ou indicador, a partir de uma série de variáveis explicativas (Hair et al., 2009; Wooldridge, 2010). No caso deste artigo, o modelo logístico para a determinação da probabilidade de dado programa em alcançar resultados acima de $80 \%$ do previsto nos "i" casos de acordo com suas "j" capacidades foi dado por:

$P[y i]=1 /(1+e-f(x j i))$, onde: $f(x j i)=\beta 0+\beta 1 * x 1 i+\beta 2 * x 2 i+\beta 3 * x 3 i+\beta 4 * x 4 i+\ldots+\varepsilon i$

$\mathrm{Yi}=$ variável dependente, ou resultados com pelo menos $80 \%$ do previsto em programas;

$\beta 0=$ constante;

$\mathrm{xj \textrm {i }}=$ variáveis independentes ou capacidades socioestatais e burocráticas;

$\beta j=$ coeficiente da variável $x j i ;$

$\varepsilon \mathrm{i}=$ erro estocástico.

O modelo capta como cada variável independente xji contribui para a ocorrência de resultados com pelo menos $80 \%$ do previsto nos casos, variável dependente yi. Permitese, assim, prever o risco ou a probabilidade de cada caso atingir ou não esse grau de resultados, de acordo com as suas características em termos de capacidades burocráticas e socioestatais. Avalia-se a significância de cada subdimensão para a composição final dos estimadores de sucesso nos resultados dos programas desenvolvidos, testando a robustez dos padrões distributivos entrevistos na análise descritiva dos dados (Wooldridge, 2010). A construção do modelo foi concretizada em blocos, sendo quatro no total (Tabela 3).

No primeiro bloco, foram calculados os estimadores e seus respectivos exponenciais para o conjunto de indicadores relativos exclusivamente à subdimensão profissionalização. O segundo bloco inseriu os indicadores relativos à subdimensão autonomia e, com base nessa inclusão, foi feito o recálculo de todos os estimadores anteriores. A terceira rodada de interações inseriu a subdimensão interfaces não coletivizadas, refazendo, na mesma linha, o recálculo dos estimadores. Por fim, o último bloco estruturou-se a partir da inclusão, no conjunto, da subdimensão interfaces coletivizadas, completando o modelo e permitindo o recálculo de todos os estimadores e seus exponenciais de maneira global. 
Tabela 3

Razões de chance (exponenciais do beta) estimados para a variável dependente Resultados alcançados nos programas com pelo menos $80 \%$ do previsto Brasil, de 2004 a 2009

\begin{tabular}{|c|c|c|c|c|c|c|c|c|c|}
\hline \multirow[t]{2}{*}{ Dimensão } & \multirow[t]{2}{*}{ Subdimensão } & \multicolumn{2}{|c|}{ Categorias } & \multicolumn{2}{|c|}{ Frequência } & \multicolumn{4}{|c|}{$\begin{array}{c}\text { Resultados com pelo menos } \\
80 \% \text { do previsto }\end{array}$} \\
\hline & & Quartil & Intervalo & $\#$ & $\%$ & Bloco 1 & Bloco 2 & Bloco 3 & Bloco 4 \\
\hline \multirow{8}{*}{$\begin{array}{l}\text { Capacidades } \\
\text { burocráticas }\end{array}$} & \multirow{4}{*}{ Profissionalização } & Q1 & Até 0,21 & 487 & 24,7 & Referência & Referência & Referência & Referência \\
\hline & & Q2 & $\begin{array}{l}\text { De } 0,21 \\
\text { até } 0,25\end{array}$ & 496 & 25,2 & 0,991 & 1,058 & 1,066 & 1,139 \\
\hline & & Q3 & $\begin{array}{l}\text { De } 0,25 \\
\text { até } 0,31\end{array}$ & 499 & 25,3 & 1,012 & $0,917 * *$ & $0,902 * * *$ & $1,017 * *$ \\
\hline & & Q4 & $\begin{array}{l}\text { De } 0,31 \\
\text { até } 0,43\end{array}$ & 487 & 24,7 & $1,157 * * *$ & $1,191 * * *$ & $1,506 * * *$ & $1,733 * *$ \\
\hline & \multirow{4}{*}{ Autonomia } & Q1 & Até 0,17 & 486 & 24,7 & - & Referência & Referência & Referência \\
\hline & & Q2 & $\begin{array}{l}\text { De } 0,17 \\
\text { até } 0,19\end{array}$ & 502 & 25,5 & - & $0,701 * *$ & $0,71^{* *}$ & $0,706 * *$ \\
\hline & & Q3 & $\begin{array}{l}\text { De } 0,19 \\
\text { até } 0,2\end{array}$ & 486 & 24,7 & - & $0,908 * *$ & $1,095^{* * *}$ & $1,193 * * *$ \\
\hline & & Q4 & $\begin{array}{c}\text { De } 0,2 \text { até } \\
0,25\end{array}$ & 495 & 25,1 & - & $1,04 *$ & $1,514 * *$ & $1,51 * *$ \\
\hline \multirow{8}{*}{$\begin{array}{l}\text { Capacidades } \\
\text { socioestatais }\end{array}$} & \multirow{4}{*}{$\begin{array}{l}\text { Interfaces não } \\
\text { coletivizadas }\end{array}$} & Q1 & Até 0,03 & 474 & 24,1 & - & - & Referência & Referência \\
\hline & & Q2 & $\begin{array}{l}\text { De } 0,03 \\
\text { até } 0,03\end{array}$ & 512 & 26,0 & - & - & 1,241 & 1,208 \\
\hline & & Q3 & $\begin{array}{l}\text { De } 0,03 \\
\text { até } 0,04\end{array}$ & 447 & 22,7 & - & - & $1,446 * *$ & $1,418^{* * *}$ \\
\hline & & Q4 & $\begin{array}{l}\text { De } 0,04 \\
\text { até } 0,09\end{array}$ & 536 & 27,2 & - & - & $1,247^{* * *}$ & $1,163 * *$ \\
\hline & \multirow{4}{*}{$\begin{array}{c}\text { Interfaces } \\
\text { coletivizadas }\end{array}$} & Q1 & Até 0,05 & 498 & 25,3 & - & - & - & Referência \\
\hline & & Q2 & $\begin{array}{l}\text { De } 0,05 \\
\text { até } 0,09\end{array}$ & 494 & 25,1 & - & - & - & $0,886 * *$ \\
\hline & & Q3 & $\begin{array}{l}\text { De } 0,09 \\
\text { até } 0,15\end{array}$ & 484 & 24,6 & - & - & - & $1,182 * *$ \\
\hline & & Q4 & $\begin{array}{l}\text { De } 0,15 \\
\text { até } 0,39 \\
\end{array}$ & 493 & 25,0 & - & - & - & $1,356 *$ \\
\hline \multicolumn{4}{|c|}{ Total de observações } & 1.969 & - & 1.969 & 1.969 & 1.969 & 1.969 \\
\hline
\end{tabular}

Fonte: Servidores Federais CGU; Filiações Partidárias TSE; SIGPlan MPOG.

*Sig. a 0,$001 ; * *$ Sig. a 0,$05 ; * * *$ Sig. a 0,1 .

Obs.: Os modelos foram montados de maneira progressiva, incluindo-se um grupo de indicadores por vez. Considerando como referência as categorias: "Baixa" (até 0,21 ) para o Corpo técnico; "Baixa" (até 0,17) para Autonomia; "Baixa" (até 0,03) para Interfaces não coletivizadas; "Baixa" (até 0,05) para Interfaces coletivizadas; o modelo completo da regressão pode ser descrito pela seguinte equação: $[P / 1-P]=\beta_{0}+B_{1}($ Corpo técnico $)+B_{2}$ (Autonomia) $+B_{3}$ (Interfaces não coletivizadas) $+B_{4}$ (Interfaces coletivizadas) $+U_{i}$.

Ao analisarmos os resultados encontrados especificamente no Bloco 1, notamos evidências de que a existência de um corpo técnico mais profissionalizado, situação concretizada pelo último quartil da subdimensão profissionalização, aumenta em cerca de $15,7 \%$ as chances de obtenção de sucesso nos resultados dos programas. Já quando passamos para os resultados do Bloco 2, ao avaliarmos o último quartil da subdimensão autonomia, concernente a um corpo técnico mais autônomo (ou menos comprometido com interesses particulares), notamos um incremento de cerca de $4 \%$ na propensão a obter maior efetividade no âmbito dos resultados apresentados pela gestão. Nesse caso, vale 
notar, o peso da subdimensão anterior, profissionalização, acaba por ser incrementado no decurso do processo, com suas chances de causar melhoria na efetividade dos resultados apresentados pelos programas, ascendendo de $15,7 \%$ para $19,1 \%$.

A análise do Bloco 3 revela que as chances de causar tal melhoria aumentam em $24,7 \%$ quando os programas, além de contarem com um corpo técnico mais profissionalizado e autônomo, fazem, também, uso relativamente intensivo de interfaces não coletivizadas no âmbito de seus respectivos processos de gestão - situação mostrada pelo último quartil da subdimensão homônima. Também nesse caso, importa notar, os estimadores das dimensões anteriores são incrementados de maneira significativa. Por fim, no Bloco 4, ao analisarmos o último quartil da subdimensão interfaces coletivizadas, referente a programas que, além de contarem com corpo técnico mais profissionalizado, autônomo e capaz de recorrer a interfaces não coletivizadas para o desempenho de suas atividades de gestão, também fazem uso mais intensivo das interfaces do tipo coletivizado, notamos um incremento em cerca de $35,6 \%$ nas chances de obtenção de sucesso nos resultados passíveis de ser alcançados.

O que esses dados nos informam é que, de fato, existe uma tendência de acentuação da importância das capacidades burocráticas estatais quando acrescidas de capacidades socioestatais no âmbito dos processos de gestão. Afinal, programas que foram capazes de combinar ambos os tipos de capacidades tiveram, como visto, maiores incrementos nas suas chances de apresentação de melhorias nos seus respectivos resultados e na efetividade de gestão das suas políticas públicas. A relevância desse fato se dá na constatação de que, como vêm afirmando diversos autores nos últimos anos (Evans, 2011), apenas o desenvolvimento de capacidades burocráticas pode não ser suficiente para obtenção de melhores resultados em políticas dessa natureza. Isso nos leva a questionar a forma pela qual esse processo se firma na prática, em especial a dinâmica que embasa a relação entre as capacidades estudadas e os custos transacionais aqui elegidos para investigação.

\section{Custos transacionais e o desenvolvimento institucional}

A questão suscitada concerne à relação entre as capacidades instaladas dos órgãos e seus respectivos potenciais de resposta em termos de formulação e produção de políticas públicas. Para investigá-la em maior profundidade, recorremos à metodologia de estudo de caso, realizando comparação entre quatro programas diferentes, desenvolvidos no âmbito da administração direta federal. Como forma de compará-los, dada a hipótese de trabalho, os parâmetros de investigação utilizados foram os próprios custos transacionais trazidos à baila neste artigo. Buscou-se checar, nesse sentido, como cada programa foi gerido em termos de dispersão decisória, centralidade política e entropia burocrática, ponderando-se as principais diferenças entre aqueles que foram desenvolvidos por órgãos 
com altas capacidades e aqueles que foram desenvolvidos por órgãos com baixas capacidades.

Para isso, foi feita breve recuperação do histórico de implementação e gestão de cada programa, de maneira a buscar conhecer o seu funcionamento, assim como avanços e limites na sua execução. Duas foram as fontes de dados principais utilizadas neste artigo: primeiro, documentos oficiais dos próprios órgãos e programas analisados; e segundo, entrevistas com gestores de cada um deles. Esses gestores, no total de oito, sendo dois por caso estudado, foram entrevistados desde que tenham sido responsáveis pela gestão no período de pelo menos um ano corrido. A avaliação de sua percepção foi importante no sentido de fornecer dicas acerca das principais variações de resultados apresentados pelas burocracias no âmbito de suas operações. Para isso, as perguntas foram direcionadas com fulcro de identificar dificuldades e falhas nos processos de gestão, com especial foco na forma e na intensidade pela qual os custos transacionais influenciaram esses elementos. As questões levantadas são as que seguem:

1. Qual sua opinião sobre o desenho do programa? Explique.

2. E qual sua opinião sobre a formatação de implementação?

3. Você considera que sua equipe era suficiente para a gestão do processo?

4. Quais as principais dificuldades enfrentadas na sua equipe?

5. Quando havia um problema específico, como ele era resolvido?

6. Havia algum contato com instâncias de controle social no nível local? Por quê?

7. Como essas instâncias influenciavam o trabalho de sua equipe e a implementação do programa?

8. Se você pudesse, o que teria mudado no processo? Por quê?

A escolha dos programas para análise seguiu três critérios específicos. O primeiro deles fundou-se nas capacidades expressas por cada órgão associadas ao seu respectivo desenvolvimento, tendo por base os dados dos índices de capacidades burocrática e socioestatal compilados. Foram elegidos casos associados a dois tipos de órgãos: primeiro, aqueles que, ao longo do período pesquisado, mostraram-se capazes de melhorar sua posição no âmbito da pontuação nos índices; e segundo, aqueles que não foram capazes de fazer tal movimento. Tendo por base esses elementos, foram priorizados programas pertencentes aos seguintes órgãos para estudo (Quadro 5): o Ministério do Desenvolvimento Social e Combate à Fome (MDS); o Ministério da Educação (MEC); o Ministério da Integração Nacional (Mina); e o Ministério dos Esportes (ME). Inicialmente, no primeiro ano pesquisado (2004), esses quatro órgãos apresentavam baixas capacidades burocráticas e socioestatais no domínio de suas ações e operações. Já ao final do período analisado (2009), dois foram capazes de ascender à categoria de altas capacidades (MDS e MEC) e os outros dois permaneceram na categoria de baixas capacidades (Mina e ME). 


\section{Quadro 5 \\ Condição de desenvolvimento institucional dos órgãos elegidos Brasil 2004-2009}

\begin{tabular}{|l|c|c|}
\hline MDS & $\mathbf{2 0 0 4}$ & $\mathbf{2 0 0 9}$ \\
\cline { 1 - 1 } MEC & $\begin{array}{c}\text { Baixa capacidade } \\
\text { burocrática }\end{array}$ & $\begin{array}{c}\text { Alta capacidade burocrática } \\
\text { Alta capacidade política }\end{array}$ \\
\cline { 1 - 1 } Mina & $\begin{array}{c}\text { Baixa capacidade } \\
\text { burocrática }\end{array}$ & $\begin{array}{c}\text { Baixa capacidade } \\
\text { burocrática }\end{array}$ \\
ME & Baixa capacidade política & Baixa capacidade política \\
\hline
\end{tabular}

Fonte: Elaboração própria.

O segundo critério adotado para a escolha dos programas concerniu à implementação e à existência efetiva de cada um deles ao longo de todo o período investigado, sem interrupções. Esse critério foi importante especialmente porque garantiu a existência de dados para análise, bem como a inexistência de eventos significativos capazes de interromper a sua respectiva execução. Por fim, o terceiro critério para escolha ateve-se à possibilidade de encontrar os agentes que, em algum momento, foram efetivamente responsáveis pela sua gestão. Isso porque, como mencionado, uma das principais fontes de informação se referiu justamente à percepção desses gestores sobre o funcionamento de cada programa. A partir da adoção desses critérios, quatro programas foram elegidos para investigação: Programa de Erradicação do Trabalho Infantil (Peti), referente ao MDS; Programa Brasil Alfabetizado (PBA), do MEC; Programa de Desenvolvimento da Agricultura Irrigada (PDAI), atinente ao Mina; e o Programa Segundo Tempo (PST), do ME. Esses programas serão analisados individualmente e, logo em seguida, examinados em conjunto.

\section{O Programa de Erradicação do Trabalho Infantil (Peti/MDS)}

Esse programa tem como objetivo retirar crianças e adolescentes de 7 a 14 anos do trabalho considerado perigoso, penoso, insalubre ou degradante, ou seja, aquele trabalho que coloca em risco a saúde e a segurança ${ }^{8}$. Operacionalmente, o programa consiste no recebimento de uma bolsa mensal por criança que for retirada do trabalho e que esteja frequentando a escola e a jornada ampliada. O financiamento advém de recursos do Fundo Nacional de Assistência Social e cofinanciamento dos estados e municípios, podendo ainda contar com a participação financeira da iniciativa privada e da sociedade civil.

A gestão do programa conta com diversos atores envolvidos, entre governos federal, estadual e municipal, além de instâncias de controle social cuja composição se dá com membros tanto do Estado quanto da sociedade. Uma vez implementado, sua gestão

\footnotetext{
8 Informações literais do website do Ministério do Desenvolvimento Social (MDS): <www.mds.gov.br>. Acesso em: 11 abr. 2014.
} 
no âmbito municipal é realizada pela chamada Comissão Municipal de Erradicação do Trabalho Infantil (CMETI). Essa comissão deve ser estruturada pelo prefeito, dotada de caráter propositivo e consultivo, sendo que seu trabalho deve ser referendado pelo Conselho Municipal de Assistência Social (CMAS). O CMAS é a instância que irá fiscalizar a aplicação dos recursos e, principalmente, irá aprovar os relatórios de prestação de contas elaborados pelo Executivo e pela CMETI.

O Peti apresentou resultados satisfatórios de cumprimento de mais de $80 \%$ das metas em 70\% do tempo do período considerado na análise, de 2004 a 2009. Apenas em dois anos específicos, 2006 e 2007, os resultados ficaram abaixo desse patamar. É interessante observar que, nesse caso, a percepção de um dos entrevistados (Entrevista 1) foi de fato positiva acerca dos resultados apresentados, ainda que tenha realizado crítica quanto à amplitude de objetivos. Segundo sua percepção, a execução se daria sob pelo menos dois grandes estigmas.

O primeiro, de caráter positivo, seria a transversalidade institucional que chancelaria a gestão. A existência de arenas híbridas, compostas por Estado e sociedade, atuando como condicionantes tanto para o repasse de recursos quanto para monitoramento efetivo das ações, seria o principal fator de sucesso. As campanhas realizadas na temática tinham, em geral, adesão de vários atores provenientes de distintas arenas, desde os próprios órgãos governamentais, como os Postos de Saúde e os Centros de Referência da Assistência Social (Cras), até mesmo os comerciantes locais, que afixavam cartazes e materiais nos estabelecimentos. Além disso, vale a pena citar também a existência do CMETI como instância criada nesses moldes, mas cujo objetivo consistia em realizar a busca de crianças e adolescentes em situação de trabalho irregular. Assim, nessa linha, a capacidade do Estado de não apenas organizar efetivamente a implementação do Peti, mas também de fazê-lo levando em consideração a sociedade, é dada como elemento explicativo fundamental para os resultados apresentados por esse programa:

Ao longo do tempo, o que o programa foi capaz de realizar se deve, em grande parte, à pactuação que o governo federal realizou principalmente com os executivos municipais. Não é possível gerir programas sem essa pactuação, na verdade. Diria inclusive que é praticamente impossível o governo federal querer agir diretamente no âmbito local sem a parceria com o governo municipal. Claro que não é simples, porque envolve muita conversa e muita (sic) ação que é realizada individualmente por cada ente, mas deve ser feita conjuntamente. Pra isso, não dá pra ficar trancado numa sala... tem as capacitações, as dúvidas da gestão. Foi sempre preciso manter um calendário de visitas, de suportes específicos para a ponta (Entrevista 1). 
Um dos maiores entraves na implementação do programa residiria na capacidade de gestão do ator estatal municipal. Em geral, especialmente nos municípios de menor porte, as dificuldades decorreriam do desconhecimento da temática por parte dos gestores locais, bem como da falta de comprometimento com prazos de prestação de contas e de elaboração de relatórios técnicos de progresso. Além disso, foi relatada existência de muita rotatividade nas equipes locais, o que servia como principal fator impeditivo de institucionalização de procedimentos efetivos de gestão do programa no território local. Isso ficava bem ilustrado no caso das capacitações:

Era preciso mediar as capacitações, por exemplo, para os agentes no âmbito
municipal. Era contratada uma executora para isso, como universidades, ou
alguma empresa, através de pregões. O problema é que isso demorava (e
demora). Não foram poucos os casos de equipes locais que foram capacitadas,
inclusive conselheiros, mas que foram inteiramente trocadas nas mudanças
de gestão. Acho que na Assistência Social isso é mais comum que nas outras
áreas. Então, para o próximo ano, tinha que repetir as intervenções, os
cursos, mas para equipes novas, gestores diferentes... (Entrevista 1).

Assim, a gestão do programa envolvia grau elevado de complexidade na coordenação das três esferas de governo no que tange, em especial, ao acompanhamento efetivo dos repasses realizados. Nesse mesmo sentido, um grande entrave à expansão de suas metas concernia não só à incapacidade do município de qualificar os técnicos e as informações associadas diretamente à ação do programa, mas também de realizar efetivamente a busca das famílias passíveis de registro e inclusão no seu âmbito de execução.

\section{O Programa Brasil Alfabetizado (PBA/MEC)}

Esse programa tem por objetivo principal a erradicação do analfabetismo, com foco nos indivíduos de 15 anos de idade ou mais. Foi criado em 2003 e sua execução consiste no apoio técnico a municípios na estruturação de módulos de estudo continuado para jovens e adultos na faixa etária considerada. A organização do programa segue um esquema que, a priori, não envolve grandes complexidades para a execução, mas depende sobremaneira da adesão voluntária dos atores governamentais para sua efetiva realização, através da celebração de convênios desenhados especificamente para esse fim.

As entidades e os governos que realizam convênios com o governo federal para sua execução são responsáveis pela seleção e pela capacitação dos indivíduos que irão atuar como alfabetizadores. Além disso, são responsáveis também pela organização de todo o processo de implementação. O Fundo Nacional de Desenvolvimento da Educação (FNDE) realiza o repasse de verbas para o custeio da formação inicial e continuada, bem como para a remuneração dos seus trabalhos durante o curso de alfabetização (Ireland, 
2012). No âmbito municipal, o governo conta com a atuação do Conselho Municipal de Educação (CME) para o acompanhamento da execução financeira, bem como, em especial, com a fiscalização da efetiva aplicação dos recursos.

Em 2004, ainda com pouco tempo de estruturação, o programa já contava com adesão de 1.667 municípios, sendo que, já em 2009, essa quantia mais do que dobrou, passando para 3.356 casos (MEC, 2010). Esse movimento de diversificação e aumento quantitativo pode ser atribuído à capacidade dos atores envolvidos de efetivamente manterem canais de contato significativos entre si. A entrevista com o gestor do programa deixou claro pelo menos três importantes aspectos nesse sentido. Em primeiro lugar, o fato de o Ministério da Educação estabelecer contato direto, através de convênios, com municípios e/ou entidades assistenciais interessadas na execução do programa. De fato, a possibilidade de negociar e interagir diretamente com os atores implementadores foi dada como elemento de relevância para sua efetiva concretização e execução, principalmente em função da celeridade dos processos e da possibilidade de evitar certos meandros burocráticos via necessidade de intermediação, por exemplo, de atores como o governo estadual, entre outros:

Os executores eram contatados através de chamadas para entrada no programa. Quem tivesse interesse, vinha, mandava os documentos para o edital. Claro que focando "naquelas" cidades com mais analfabetismo. Depois ampliamos para outras, porque tinha pouca gente no começo. Daí, a celebração do convênio era até rápida se comparar com as licitações normais (Entrevista 2).

O segundo ponto levantado como importante componente na gestão foi a capacidade de fiscalização efetiva da execução dos recursos no âmbito municipal. Foi possível disponibilizar pessoal do MEC, por exemplo, para realização de visitas técnicas aos municípios e observar de perto as atividades empreendidas. Além disso, esse potencial de fiscalização era ampliado em função das parcerias estabelecidas com os Conselhos Municipais de Educação (CME), dada a patente dificuldade do ministério em realizar missões in loco em todos os mais de 3.350 municípios conveniados.

O terceiro elemento citado na entrevista concerne às principais dificuldades enfrentadas por esse arranjo administrativo, sendo que a principal delas residia no estabelecimento e na padronização de instrumentos e processos operacionais voltados à fiscalização efetiva da execução e correta aplicação dos recursos do programa. De Fato, em 2004 e 2006, o Brasil Alfabetizado foi objeto de auditoria do Tribunal de Contas da União, e um dos principais gargalos apontados no processo foi exatamente esse quesito (TCU, 2006). Em 2004, por exemplo, os fiscais do TCU constataram que, na verdade, o programa não contava com uma estrutura mínima e/ou mesmo adequada para monitoramento sequer no que tange à execução orçamentária. As prestações de conta não 
eram acompanhadas de maneira efetiva pelos gestores e sequer foram encontrados balancetes referentes a vários meses de gestão.

A entrevista realizada revelou que, de fato, a atividade de fiscalização, ainda que importante, carecia de melhorias significativas. Em primeiro lugar, a própria capacidade de visita técnica do MEC era limitada. Apenas alguns municípios podiam ser visitados por vez e, quando essas visitas aconteciam, via de regra os governos municipais demonstravam certa resistência, pois achavam que se tratava muito mais de uma fiscalização e auditoria realizada pelo governo federal nos seus processos e contas:

Era difícil convencer os prefeitos de que não se tratava de auditoria. Talvez essa fosse a parte mais complicada, porque, dependendo da forma como éramos recebidos, não tínhamos acesso a nenhum documento (Entrevista 2).

Além dessa questão, nos locais onde não era possível a presença do MEC, a pactuação com os Conselhos Municipais também poderia ser problemática, particularmente no caso daqueles municípios que não contavam com Conselho Municipal de Educação. Nos casos em que esse último estava presente, era possível esperar uma efetiva fiscalização das atividades desempenhadas pelos executores dos convênios, inclusive com visitas dos próprios membros do conselho às atividades. Já nos casos em que esse órgão inexistia, era preciso realizar acordos com o Conselho Municipal de Assistência Social, com a desvantagem de esse conselho já ter em sua pauta questões próprias do campo da assistência social e nem sempre sobrava recursos como tempo e pessoal para fiscalizar programas de outras áreas, como, nesse caso, da educação. A despeito desses embaraços, a parceria com os Conselhos Municipais, vale dizer, não era de todo desprezível, porque, mesmo não tendo condições de efetivamente realizar visitas aos executores dos contratos, eles recebiam denúncias provindas da própria sociedade acerca de irregularidades percebidas no programa. Essas denúncias eram formalizadas e remetidas à coordenação do PBA no MEC, que tinha a possibilidade de coletar, com isso, indícios importantes acerca da situação de seu programa em determinado município.

\section{O Programa Segundo Tempo (PST/ME)}

Esse programa é executado desde 2003 no âmbito do Ministério do Esporte, instituído pelo Decreto no 4.668/2003, junto à Secretaria Nacional de Esporte Educacional. Seu principal objetivo consiste, segundo redação dada por esse decreto, na democratização do acesso à prática e à cultura do esporte como instrumento educacional, visando ao desenvolvimento integral de crianças, adolescentes e jovens, como meio de formação da cidadania e melhoria da qualidade de vida. Seu desenho operacional se conforma na concretização de núcleos esportivos a partir da disponibilização de espaços físicos para desempenho das atividades planejadas, material esportivo e equipe multidisciplinar composta não apenas por profissionais da área de educação física, mas também 
assistentes sociais, psicólogos e pedagogos. Já seu arranjo institucional se conforma pela elaboração de acordos técnicos de cooperação diretamente entre o governo federal (através do Ministério do Esporte) e as administrações municipais. Em alguns casos, acordos também são firmados com os governos estaduais, desde que estes apresentem planos específicos de repasse de recursos e de pactuação com municípios.

É prevista a pactuação e a execução das atividades por entidades assistenciais, desde que atreladas à área da educação e que tenham acordos firmados com as escolas públicas para operacionalização das ações e, em especial, trabalho com os profissionais envolvidos no projeto. Em adição, o processo de pactuação pressupõe também a presença de outro agente municipal de significativa importância, que é o Conselho Municipal do Esporte. A atuação dessa instância se daria na fiscalização da aplicação dos recursos transferidos pelo governo federal, tendo por base a perspectiva de operacionalização efetiva do programa. O foco de seu trabalho estaria muito menos na fiscalização orçamentária do PST e muito mais no monitoramento da realização efetiva de atividades previstas nos acordos técnicos de cooperação firmados.

Em 2009 o PST já estava presente em mais de 900 municípios, contando com mais de 234 convênios e com uma estimativa de atendimento de mais de 800 mil crianças e adolescentes no período (ME, 2010). É intrigante observar, todavia, que, de acordo com o SIGPlan, entre os anos de 2004 e 2009, em apenas um deles (sendo especificamente o ano de 2008) o gestor do programa declarou que os resultados alcançados estiveram com pelo menos $80 \%$ do originalmente previsto. Para todos os demais anos, esse resultado ficou no patamar de abaixo de $60 \%$ do previsto. Esse resultado pode ser mais esclarecido através da entrevista 6 (trecho citado abaixo) realizada com o gestor do programa que estava na sua condução entre os anos de 2007 e 2009. Em sua visão, pelo menos três grandes problemáticas estavam atreladas à gestão do programa.

Em primeiro lugar, a equipe do próprio Ministério do Esporte não era de fato especializada na área, mas sim na gestão orçamentária do programa. Essa falta de conhecimento da temática levou a entraves na fiscalização efetiva das atividades, porque o ministério não dispunha de uma rede de fiscais para além do cumprimento das ações de execução orçamentária. A segunda problemática estava ligada às negociações que envolviam o repasse dos recursos. O relato, nesse caso, concerne à forma de descentralização destes através de acordos técnicos de cooperação, os quais, via de regra, não estavam atrelados a planilhas de referência em termos de preços de produtos e serviços. Essa problemática específica levou a uma reformulação gerencial completa do PST em 2008, com os novos projetos sendo submetidos a planilhas dessa natureza, compiladas e publicadas por instituições como o IBGE e o Dieese. A questão é que já havia muitos convênios e acordos firmados nos anos anteriores que ainda estavam vigentes, mas que não entrariam nessa nova lógica de gestão: 
Fiz a reformulação completa do fluxo de trabalho do Departamento. Os analistas foram treinados e capacitados na Esaf, inclusive contando com cursos e certificados. Claro que a maioria era emprestada de outros ministérios, o que causava problemas... às vezes saíam e nem retornavam e a gente perdia o treinamento feito (Entrevista 6).

A terceira e última questão que se estruturava como problemática na gestão do programa concernia à fiscalização efetiva das atividades desempenhadas. Era muito difícil enviar pessoal para verificar e acompanhar as atividades in loco em função da fragmentação da equipe no âmbito efetivo de gestão do programa. Assim, o monitoramento e a aferição de sua efetividade ficavam totalmente a cargo dos parceiros locais, especialmente o Conselho Municipal do Esporte. Todavia, na maioria dos municípios nos quais o programa estava em execução, esse conselho inexistia ${ }^{9}$ e, por isso, todo o trabalho de fiscalização acabava por redundar basicamente na prestação de contas das próprias entidades executoras.

\section{O Programa Desenvolvimento Agricultura Irrigada (PDAI/Mina)}

Esse programa foi criado no ano de 2003, tendo por objetivo o fornecimento de crédito para a implantação de sistemas de irrigação, assim como subsídios para aquisição de equipamentos e agilização burocrático-processual no licenciamento e na outorga de projetos dessa natureza, com foco em pequenos agricultores (Mina, 2012). Dentre suas diretrizes operacionais, pelo menos uma se destaca: a garantia de coordenação para implantação de projetos diretamente com as comunidades rurais, através de suas associações, cooperativas e/ou sindicatos. O programa é gerido de forma descentralizada, tendo por foco o governo federal e esses atores elegidos para serem beneficiários diretos de suas ações. A escolha das instituições é, ela própria, uma atividade descentralizada, realizada pelas autarquias do Ministério da Integração, que são o Departamento Nacional de Obras Contra as Secas (DNOCS), o Departamento Nacional de Obras de Saneamento (DNOS), a Superintendência para o Desenvolvimento do Nordeste (Sudene) e a Companhia de Desenvolvimento do Vale do Rio São Francisco (Codevasf). Essas instâncias realizam a seleção direta de comunidades e/ou agrupamentos rurais para implantação do programa e prestação de auxílio técnico na sua efetivação.

Os resultados apresentados pelo programa foram avaliados no patamar de abaixo de $40 \%$ do esperado para todos os anos considerados na amostra do SIGPlan, de 2004 a 2009. A entrevista realizada com o gestor desse programa, que esteve na sua chefia nos anos de 2006 a 2008, foi reveladora nesse sentido. Pelo menos três problemáticas foram

\footnotetext{
9 De fato, de acordo com a pesquisa Munic (IBGE, 2005), cerca 5\% dos municípios brasileiros possuíam Conselho Municipal do Esporte em 2005. Em 2009, a pesquisa constatou que esse percentual era de pouco mais de $11 \%$. E, mais recentemente, a última pesquisa, referente ao ano de 2013 , constatou percentual de aproximadamente $19 \%$.
} 
citadas como significativos entraves à melhoria de eficiência na gestão do programa. O primeiro entrave tem relação direta com a situação de gestão dentro da própria administração federal. Segundo o entrevistado, existe uma alta rotatividade de servidores não apenas no próprio Mina, mas principalmente nas autarquias. Essa rotatividade tem por base frequentes pedidos dos próprios servidores para exercício descentralizado de carreira em outros órgãos ou, ainda, a admissão em outros concursos e carreiras.

O segundo entrave dado como fundamental concerne à descentralização administrativa. Atividades rotineiras na gestão do programa, como a consolidação de processos orçamentários, a confecção de planos de trabalho ou, ainda, a coleta de dados para fins de monitoramento e avaliação, são realizadas pelas autarquias envolvidas no processo. O grande problema nessa linha concerne à inexistência de uma sistemática de centralização, padronização e conformação desses processos em documentos únicos e padronizados que consigam prover uma visão ampla e efetiva do andamento dos projetos. Nesse sentido, a gestão descentralizada torna-se um entrave burocrático significativo para o programa, pois os próprios órgãos envolvidos no processo não raro são incapazes de trocar informações e sistemáticas de trabalho entre si.

Por fim, o último grande entrave relatado concerne à falta de consulta e diálogo com outros agentes afetados pelas atividades e ações desenroladas no âmbito do programa. Via de regra, existe, segundo o entrevistado, uma diretiva comum entre as autarquias de estruturarem, autonomamente, os grupos e comunidades rurais para a composição dos trabalhos do programa. Isso quer dizer que, em geral, mesmo aqueles grupos comunitários, associações e/ou cooperativas previamente existentes tendem a ser ignorados em prol da criação de agrupamentos condizentes com os objetivos e interesses de cada autarquia. Ademais, é sintomático, também, a quase inexistência de diálogo com os governos estadual e municipal, quiçá com órgãos e interfaces socioestatais locais, os quais, via de regra, não são consultados acerca dos objetivos traçados para o seu território, muito menos acerca de planejamentos para futuras ações.

\section{Análise comparativa dos programas}

A análise do histórico dos programas e da percepção dos seus respectivos gestores revelou importantes aspectos e dicas no que toca à relação entre capacidades burocrática e socioestatal e resultados apresentados em termos de políticas públicas (Quadro 6). Observamos que os programas Peti e PBA obtiveram, no geral, alcance satisfatório de resultados, ao passo que PDAI e PST obtiveram resultados muito abaixo do esperado. A partir disso, importa analisar se e como as capacidades instaladas de cada um deles contribuíram para esses resultados, especialmente considerando o caráter e o sentido das correlações previstas e entrevistas no modelo inferencial estruturado na seção anterior.

No que tange às capacidades burocráticas, fica claro que o desenvolvimento institucional dos programas Peti e PBA foi muito mais linear e consistente do que os outros 
dois considerados. Os gestores afirmaram que os respectivos corpos técnicos eram adequados para o trabalho e que essa adequação se dava tanto no conhecimento que os trabalhadores detinham da temática quanto na própria disponibilidade dos órgãos para criação de carreiras próprias para suas respectivas gestões. Esse movimento, vale dizer, não foi observado para os casos de PST e PDAI, o que se refletiu nos seus prognósticos nesse caso, já que os gestores afirmaram, via de regra, que o corpo técnico não era afeto à área de trabalho e, geralmente, era cedido por outros órgãos.

Esse movimento observado nas capacidades burocráticas não destoou muito daquele observado no caso das capacidades socioestatais. Nesse caso, Peti e PBA tiveram, na percepção dos gestores, importante interação com interfaces socioestatais territoriais, em especial os Conselhos Gestores Municipais. Isso ficou patente quando observamos que os processos envolvidos na implementação de ambos os programas contavam, efetivamente, com a submissão dos seus respectivos processos decisórios a essas instâncias. Já no caso de PST e PDAI, parece que esse contato foi bem menor ou mesmo inexistente, seja para fins de implementação, seja para fins até mesmo de fiscalização. 


\section{Quadro 6 \\ Avaliação dos programas elencados para análise, segundo percepção dos entrevistados}

\begin{tabular}{|c|c|c|c|c|c|}
\hline & \multicolumn{2}{|c|}{ Capacidades } & \multirow{2}{*}{ Dispersão decisória } & \multirow{2}{*}{$\begin{array}{c}\text { Centralidade } \\
\text { política }\end{array}$} & \multirow{2}{*}{ Entropia burocrática } \\
\hline & Burocráticas & Socioestatais & & & \\
\hline Peti & $\begin{array}{l}\text { Corpo técnico } \\
\text { afeto à área, } \\
\text { inclusive } \\
\text { contando com } \\
\text { carreiras próprias }\end{array}$ & $\begin{array}{l}\text { Estratégia clara de } \\
\text { interação com conselhos e } \\
\text { órgãos participativos } \\
\text { territoriais, especialmente } \\
\text { para implementação }\end{array}$ & $\begin{array}{l}\text { Definição clara de papéis e } \\
\text { objetivos dos atores ao } \\
\text { longo do processo, sem } \\
\text { mudanças bruscas na } \\
\text { operacionalização }\end{array}$ & $\begin{array}{l}\text { Efeito de } \\
\text { fortalecimento } \\
\text { do programa, } \\
\text { ao contrário } \\
\text { do que se } \\
\text { previa para o } \\
\text { custo }\end{array}$ & $\begin{array}{l}\text { Burocratas em } \\
\text { constante contato } \\
\text { entre si e com outros } \\
\text { atores, facilitando } \\
\text { coordenação }\end{array}$ \\
\hline PBA & $\begin{array}{l}\text { Corpo técnico } \\
\text { afeto à área, } \\
\text { inclusive } \\
\text { contando com } \\
\text { carreiras próprias }\end{array}$ & $\begin{array}{l}\text { Estratégia clara de } \\
\text { interação com conselhos e } \\
\text { órgãos participativos } \\
\text { territoriais, especialmente } \\
\text { para fiscalização }\end{array}$ & $\begin{array}{l}\text { Definição clara de papéis e } \\
\text { objetivos dos atores ao } \\
\text { longo do processo, sem } \\
\text { mudanças bruscas na } \\
\text { operacionalização }\end{array}$ & $\begin{array}{l}\text { Efeito de } \\
\text { fortalecimento } \\
\text { do programa, } \\
\text { ao contrário } \\
\text { do que se } \\
\text { previa para o } \\
\text { custo }\end{array}$ & $\begin{array}{l}\text { Burocratas em } \\
\text { constante contato } \\
\text { entre si e com outros } \\
\text { atores, facilitando } \\
\text { coordenação }\end{array}$ \\
\hline PST & $\begin{array}{l}\text { Corpo técnico, via } \\
\text { de regra, não } \\
\text { afeto à área e } \\
\text { cedido por outros } \\
\text { órgãos }\end{array}$ & $\begin{array}{l}\text { Pouca ou nenhuma } \\
\text { interação com instituições } \\
\text { participativas locais, } \\
\text { atuando diretamente com } \\
\text { os convenentes, seja para } \\
\text { implementação, seja para } \\
\text { fiscalização }\end{array}$ & $\begin{array}{l}\text { Técnicos atuando, em geral, } \\
\text { de maneira autônoma com } \\
\text { cada agente de convênio, } \\
\text { sem interlocução mútua, } \\
\text { variando muito o seu } \\
\text { desenho de implementação }\end{array}$ & $\begin{array}{l}\text { Dominado } \\
\text { politicamente } \\
\text { por partidos } \\
\text { específicos, } \\
\text { sem clara } \\
\text { definição de } \\
\text { longo prazo } \\
\end{array}$ & $\begin{array}{l}\text { Burocratas com pouca } \\
\text { interação entre si e } \\
\text { entre outros atores } \\
\text { envolvidos nos } \\
\text { programas }\end{array}$ \\
\hline PDAI & $\begin{array}{l}\text { Corpo técnico, via } \\
\text { de regra, não } \\
\text { afeto à área e } \\
\text { cedido por outros } \\
\text { órgãos }\end{array}$ & $\begin{array}{l}\text { Pouca ou nenhuma } \\
\text { interação com instituições } \\
\text { participativas locais, } \\
\text { atuando diretamente com } \\
\text { os convenentes, seja para } \\
\text { implementação, seja para } \\
\text { fiscalização }\end{array}$ & $\begin{array}{l}\text { Atuação direta com famílias } \\
\text { pode ter gerado situação de } \\
\text { pouca interlocução entre os } \\
\text { demais agentes do plano, } \\
\text { com bastante variabilidade } \\
\text { no seu desenho de } \\
\text { implementação }\end{array}$ & $\begin{array}{l}\text { Dominado } \\
\text { politicamente } \\
\text { por partidos } \\
\text { específicos, } \\
\text { sem clara } \\
\text { definição de } \\
\text { longo prazo } \\
\end{array}$ & $\begin{array}{l}\text { Burocratas com pouca } \\
\text { interação entre si e } \\
\text { entre outros atores } \\
\text { envolvidos nos } \\
\text { programas }\end{array}$ \\
\hline
\end{tabular}

Fonte: Entrevistas com gestores dos programas.

É interessante observar como essas diferentes formas de se organizar em torno das capacidades se refletiram nos custos transacionais associados à gestão de cada caso. No que tange, por exemplo, ao aspecto da dispersão decisória, isso ficou bastante claro. Por um lado, Peti e PBA parecem não ter tido problemas em lidar com as instâncias de tomada de decisão de caráter colegiado. Como visto, essas instâncias atuavam, entre outras atribuições, até mesmo na fiscalização das ações desenvolvidas em cada programa. Não houve relato de que a relação dos técnicos com esse processo tenha sido conflituosa ou mesmo impeditiva do trabalho, pelo contrário, parece que, na verdade, a percepção era de que esse tipo de instância servia muito mais como importante aporte à execução e à fiscalização do próprio programa. Esses técnicos, assim, demonstraram capacidade significativa de lidar com uma miríade de atores interessados no desenvolvimento de suas ações, a partir de instrumentos operacionais específicos, que foram as interfaces socioestatais por eles elegidas e referendadas em cada caso.

O mesmo movimento, vale dizer, foi muito pouco observado para os casos de PST e PDAI, em que tais instâncias se fizeram relativamente bem menos presentes, mesmo 
quando contaram com uma diversidade de atores tomando parte e se envolvendo no processo de implementação. O que claramente parece ter variado nesses casos concerne à forma pela qual os técnicos de ambos os programas lidavam com esses atores, através de abordagens e negociações muito mais individualizadas do que coletivas, isso quando essas próprias negociações existiam. Através dessa abordagem, diferentes tipos de acordo eram realizados ao longo do processo, mas sem haver uma coordenação mais ampla do cenário de implementação. Assim, seja pela falta de interfaces socioestatais que Ihes dessem respaldo e aporte para o estabelecimento efetivo dessa coordenação (tal como nos casos anteriores), seja pela própria falta de preparo para tanto, nos casos de PST e PDAI a dispersão decisória se conformou e se estruturou de uma maneira muito mais intensa e conflituosa do que no caso dos outros dois programas.

O segundo custo transacional se refere à centralidade política. Nesse caso, é preciso analisar mais amplamente os programas, já que, por um lado, Peti e PBA tinham por origem órgãos afetos a duas áreas, educação e assistência social, que eram estratégicas para o governo à época, ao passo que PST e PDAI se atrelavam a áreas historicamente relegadas a segundo plano no país, notadamente o esporte e a agricultura de pequeno e/ou microporte (Cardoso Jr., 2012). Por outro lado, podemos correlacionar esse alto grau de centralidade política e o desenvolvimento burocrático dos órgãos responsáveis por Peti e PBA.

O MDS e o MEC foram capazes de fortalecer suas respectivas capacidades através da constituição de um corpo técnico próprio e, principalmente, afeto às suas respectivas missões institucionais (Vaz, 2016). Em termos de desenvolvimento corporativo, isso implicou a constituição de um corpo técnico-burocrático forte, disciplinado e efetivamente identificado com as suas atividades e operações. Já no caso dos outros dois programas, seus respectivos órgãos de pertencimento, Mina e do $M E$, tiveram um desenvolvimento institucional pouco linear, tendo por principal consequência a falta de identidade burocrática de maneira geral (Vaz, 2016). As carreiras próprias de cada um deles, quando existentes, foram pouco fomentadas e valorizadas, seja através da realização de concursos públicos, seja através da efetiva concentração de suas atividades em áreas realmente afetas à temática com a qual lidam.

O outro lado da centralidade política se refere à ingerência sofrida pelas áreas priorizadas. Ao contrário dessa expectativa, todavia, parece que Peti e PBA não foram tratados como políticas casuísticas pelo governo, mas tiveram continuidade durante um tempo relativamente longo, bem como expansão de cobertura dada como significativa. Talvez a explicação para isso se dê por duas fontes. Primeiro, tanto educação quanto assistência social são áreas dotadas de um forte componente de ativismo no âmbito de suas temáticas e perspectivas de atuação (Jaccoud, 2009). A criação do Suas, por exemplo, é reflexo dessa forte participação que os profissionais da assistência social detêm no seu campo de trabalho, sendo que o mesmo se repete para a educação (Vidal, 2003). Em adição a isso, a criação de um corpo burocrático relativamente forte, contando, ainda, com 
uma capacidade socioestatal recrudescida, parece ter servido como anteparo de grande importância às ingerências políticas, sendo isso um resultado importante no que toca à implementação de políticas públicas que sejam menos governamentais e mais estatais.

O mesmo, vale dizer, não foi observado para o caso de PST e PDAI, que tiveram histórias diferentes. Ambos os programas tiveram pouca linearidade no seu desenvolvimento, especialmente se considerarmos os resultados alcançados por cada um deles. A rotatividade de técnicos parece ter impactado diretamente sua implementação. Nesse mesmo sentido, o fato de que muitos técnicos não eram da área e mesmo da própria burocracia parece ter também contribuído para esse estado de coisas, especialmente em função dos cargos ocupados por agentes não concursados, sugerindo maior facilidade de sua captura por interesses particulares.

O último custo transacional a ser considerado é o da entropia burocrática. Nesse caso, gestores do Peti e PBA afirmaram, em geral, que os papéis dos atores estavam bem definidos no âmbito dos projetos, e que não houve mudanças bruscas nesses papéis no momento de sua implementação. Isso garantiu continuidade e segurança institucional para os trabalhos de todos os agentes envolvidos. Já no caso de PST e PDAI, parece que situação contrária se estabeleceu: a interlocução entre os agentes era muito rara, bem como a atuação bastante individualizada, em função do desenho dos programas. Isso fez com que cada agente atuasse de uma maneira específica e, em alguns casos, que fosse possível observar mudanças bruscas na implementação por determinados atores, embora não houvesse uma fiscalização efetiva central. Isso implica que o programa pode ter sido implementado de diversas formas, nos diferentes lugares, sem que os próprios agentes institucionais dialogassem entre si, ou mesmo com o centro de implementação.

\section{À guisa de conclusão}

Não é uma discussão banal o papel desempenhado pelo Estado na institucionalização e promoção de políticas públicas nas diversas áreas temáticas. Por um princípio racional de concretização de políticas nessa linha, é mister observar que, à consagração de direitos na esfera legislativa e sua aplicabilidade pela esfera jurídica deve corresponder um Estado capaz de efetivar políticas interventivas de maneira eficaz e eficiente, principalmente na perspectiva de atendimento às demandas apresentadas pela população. Essa capacidade do Estado de intervir está ligada não apenas à sua capacidade técnica de analisar, planejar e implementar ações e programas, mas de fazê-lo tendo por base e aporte os próprios indivíduos e grupos potencialmente impactados por essas atividades. Eis o principal desafio enfrentado pelos agentes estatais nas democracias modernas: como aprimorar essa integração Estado-sociedade nos espaços governamentais onde ela já existe e, principalmente, como criar essa relação onde ela inexiste?

Este artigo pretendeu lidar com essa questão sob pelo menos dois pontos de vista. Primeiro, apresentando o argumento de que o Estado se constitui como ator central na 
promoção de políticas públicas; e, segundo, defendendo que, para o desempenho desse papel, tendo por base o cenário sociopolítico das democracias modernas, as capacidades socioestatais - e não apenas as capacidades burocráticas - se revelam elementos essenciais nos processos públicos decisórios. Uma vez combinados, esses dois argumentos nos permitem compreender como, atualmente, o Estado pode elaborar e efetivar intervenções na sociedade e efetivamente ser capaz de cumprir os objetivos traçados.

As análises de regressão e correlação empreendidas aqui nos mostraram que, embora as capacidades burocráticas e socioestatais sejam, em geral, desenvolvidas de maneira independente, sua estruturação conjunta tende a gerar um sistema de mútua retroalimentação. Órgãos nos quais se observaram, por exemplo, maiores capacidades socioestatais também se associaram a tendências de apresentar maiores capacidades burocráticas, e vice-versa. Assim, ficou clara neste artigo uma propensão de que o desenvolvimento de capacidades socioestatais fortalece as capacidades burocráticas já existentes em cada órgão da administração pública. Além disso, a análise do período de 2004 a 2009 mostrou claramente uma associação positiva entre o desenvolvimento de ambas as capacidades e uma melhoria na resposta das instituições públicas aos processos de gestão e implementação de políticas. Quanto maior o reforço de ambos os ativos, conjuntamente, melhores as chances de dado programa atingir resultados mais que satisfatórios nas suas execução e operacionalização de uma forma geral - tal como na métrica adotada na análise da variável dependente da regressão no que tange à obtenção de resultados com pelo menos $80 \%$ do originalmente previsto.

A constatação dessa variabilidade no desenvolvimento efetivo das capacidades implicou diretamente $o$ questionamento das condições de sua estruturação e desenvolvimento. O que levou os órgãos a situações tão diferenciadas em termos de gestão? Sob que condições esse processo se estruturou de uma forma geral? A consideração a ser feita concerniu aos resultados apresentados pelos programas aqui analisados em profundidade, sendo que cada qual conta, como visto, com desenhos institucionais muito específicos, que tendem a considerar em diferentes graus o contato, por exemplo, com interfaces socioestatais.

No caso do Peti e do PBA, esse desenho privilegia a negociação com diversos órgãos de controle social, como Conselhos Gestores, bem como com os governos envolvidos na gestão. Dessa forma, ações como a fiscalização do cumprimento efetivo das atividades acordadas tendem a ser desempenhadas de maneira conjunta e pactuada, embora esse modelo também enfrente uma série de dificuldades, como visto. Ainda assim, sua efetivação parece favorecer a divisão do trabalho entre os agentes num claro sistema de parceria, no qual as informações são efetivamente trocadas e os ajustes necessários são realizados de maneira concisa. Já no caso do PST e do PDAI, observamos desenhos que privilegiam uma gestão de caráter muito mais top-down. É singular, por exemplo, o Programa de Agricultura Irrigada, que sequer tende a estabelecer negociações claras e/ou mesmo diretas com os estados e municípios para a efetivação de suas ações. Nesse mesmo sentido, o Programa 
Segundo Tempo tende a estabelecer parcerias com um número limitado de agentes, ficando impossibilitado, inclusive, de proceder às fiscalizações efetivas das atividades porque não é capaz de atuar numa lógica de parceria com instituições como Conselhos Gestores, dentre outras.

Enfim, podemos dizer que, desde a ótica eminentemente quantitativa até a ótica qualitativa, há indícios significativos que apontam na direção de apresentação de melhores resultados em políticas públicas através da combinação de capacidades burocráticas e socioestatais no âmbito da gestão governamental. E isso através dos impactos que essa configuração de capacidades tem nos custos transacionais associados ao desenvolvimento de cada programa, tal como visto na seção anterior. Dessa forma, não é difícil imaginar a razão que faz com que o desenvolvimento de ambas as dimensões seja uma questão de seminal importância para instituições governamentais no cenário atual. Ainda assim, vale dizer, é importante tecer considerações sobre futuras agendas de pesquisa sobre essa questão. A primeira delas se refere, por exemplo, ao papel efetivo desempenhado pelas interfaces socioestatais nos processos de gestão pública. No caso deste artigo, essa questão sobressaiu em relação aos Conselhos Gestores municipais.

Segundo os entrevistados, esses conselhos eram importantes, mas nem sempre existiam nos municípios. Nesse caso, em geral, as possibilidades de denúncia e formalização de contato com os órgãos gestores eram repassadas, através de pactuação, a outros conselhos eventualmente existentes no município, como Conselhos municipais de Assistência Social ou mesmo de Saúde. Esse formato de organização levantou a questão da potencial sobrecarga de atividades dos conselhos em nível municipal. Nos locais onde inexistem Conselhos de Educação, por exemplo, questões ligadas à área e, em especial, relacionadas aos programas executados pela área são tratados pelos Conselhos de Assistência Social, por exemplo, tal como relatado nas entrevistas. Certamente essa constitui uma questão para futuros estudos e pesquisas.

Outra questão que merece maior aprofundamento analítico diz respeito a um avanço na literatura acerca das próprias capacidades burocráticas e socioestatais. No caso dessas últimas, foi possível notar que, quanto à ecologia de interfaces socioestatais, cabe ao gestor adotar aquela que melhor se ajusta aos objetivos e às atividades de seu programa. Todavia, é preciso avançar teoricamente sobre quais seriam as melhores alocações em termos de desenhos institucionais e programas desenvolvidos. Nesse caso, a hipótese de pesquisa concerne à possível existência de uma alocação perfeita entre interfaces e programas capaz de maximizar o contato entre Estado e sociedade, tendo por base as diversas áreas de políticas públicas, bem como as de gestão governamental.

Nessa mesma linha, também o conceito de capacidades burocráticas merece melhor refinamento do que atualmente a literatura Ihe confere. Nesse caso, importa investigar a possível existência de diferentes tipos de capacidades burocráticas que sejam melhores ou mais adequadas aos diferentes tipos e variações de programas, áreas e desenhos de gestão governamental. Certamente, tal como neste artigo, a literatura vem, via de regra, 
pressupondo que o conceito de capacidades burocráticas é único e deve ser aplicado de maneira linear nos diversos órgãos e programas. Futuras pesquisas, no entanto, podem buscar a relativização do conceito, enfrentando o desafio de, ao mesmo tempo, manter a comparabilidade entre os casos de estudo para sua avaliação em termos de performance e benchmarking.

\section{Referências bibliográficas}

Abers, R.; Serafim, L.; TAtagibA, L. "Repertórios de interação Estado-sociedade em um Estado heterogêneo: a experiência na era Lula". Dados, vol. 57, no 2, p. 325-357, 2014.

Albuquerque, E. M. Agenda Rosdolsky. Belo Horizonte: Editora UFMG, 2013.

AlmeidA, D. R.; CunhA, E. S. "Brazilian social assistance policy: an empirical test of the concept of deliberative systems". Critical Policy Studies, vol. 10, p. 1-21, 2016.

AvrITZer, L. Participatory institution in democratic Brazil. Baltimore: John Hopkins University Press, 2009.

"Entre o conflito de interesses e a nova institucionalidade política". Novos Estudos Cebrap, vol. 103, p. 211-217, 2015.

BARRIOS, R. S. L. "Entropía institucional en los programas mexicanos de estímulos académicos: un análises por intersticios". Revista Gestión y Estratégia, n 34, 2008.

Besley, T.; Persson, T. "Repression on civil war?". American Economic Review, vol. 99, n², p. 292297, 2009.

BosCHI, R. R.; GAITÁN, F. "Intervencionismo estatal e políticas de desenvolvimento na América Latina". Caderno CRH, vol. 21, n० 53, p. 303-319, 2009.

BRADY, D. "Rethinking the sociological measurement of poverty". Social Forces, vol. 81, no 3, 715$751,2003$.

BRASIL, F. P. D., et al. "Participação, desenho institucional e alcances democráticos: uma análise do Conselho das Cidades (ConCidades)". Revista de Sociologia e Política, vol. 21, n 48, p. 5-18, 2013.

Bresser-PereirA, L. C. "From the national-bourgeoisie to the dependency interpretation of Latin America (LAP)". Latin American Perspectives, vol. 38, n 3, 2011.

Bresser-PereirA, L. C.; Theuer, D. "Um Estado novo-desenvolvimentista na América Latina?". Economia e Sociedade, vol. 21, número especial, 2012.

CAmpos, R. "A geleia filantrópica". Folha de S. Paulo, 23 abr. 1995. Disponível em:

<https://www1.folha.uol.com.br/fsp/1995/4/23/brasil/5.html>. Acesso em: 12 jan. 2018.

CARDoso JR., J. C. "Planejamento governamental e gestão pública no Brasil: elementos para ressignificar o debate e capacitar o Estado". Texto para Discussão no 1584, Ipea, 2012.

. Planejamento, democracia e desenvolvimento no Brasil: perspectivas à luz das capacidades estatais e instrumentos governamentais. In: CALIXTRE, A. B.; BIANCARELLI, A. M.; CiNTRA M. A. M. (orgs.). Planejamento, democracia e desenvolvimento no Brasil: perspectivas à luz das capacidades estatais e instrumentos governamentais. Brasília: Ipea, vol. 1, p. 79-114, 2014.

CGU - Controladoria-Geral da União. Banco de dados dos servidores da administração pública federal. Disponível em: <www.portaldatransparencia.gov.br>. Acesso em: 10 maio 2014. 
DISPERSÃO DECISÓRIA, CENTRALIDADE POLÍTICA E ENTROPIA BUROCRÁTICA

ChAng, H. J. The political economy of industrial policy. New York: Palgrave Macmillan, 1995. . Globalization, economic development and the role of the State. London: Zed Books, 2003.

CoelHo, V. S. R. P.; Nobre, M. (orgs.). Participação e deliberação: teoria democrática e experiências institucionais no Brasil contemporâneo. São Paulo: Editora 34, 2004.

COLES, J. W.; HESTERLY, W. S. "Transaction costs, quality, and economies of scale: examining contracting choices in the hospital industry". Journal of Corporate Finance, vol. 4, n 4, p. 321-345, 1998.

CUNHA, E. S. M. Inclusão social e política: o desafio deliberativo dos Conselhos Municipais de Assistência Social. In: AVRITZer, L. (org.). A dinâmica da participação local no Brasil. São Paulo: Cortez, 2011.

EdighejI, O. (ed.) Constructing a democratic developmental State in South Africa. Constructing the 21st century developmental State. Cape Town: HSRC Press, 2010.

Evans, P. Embedded autonomy - States and industrial transformation. New Jersey: Princeton Press, 1995.

. "Building bridges across a double divide: aliances between US and Latin American labor and NGOS". Development in Practice, vol. 14, n 1-2, p. 34-47, 2004.

"The capability enhancing developmental State: concepts and national trajectories". Texto para Discussão, n 63, Cede, Niterói, 2011.

EVANS, P.; HeLleR, P. Human development, State transformation and the politics of the developmental State. Oxford: Oxford University Press, 2013. Disponível em: <http://goo.gl/J8mx2W>. Acesso em: 7 nov. 2018.

EVANS, P.; RAUCH, J. "Bureaucracy and growth: a cross-national analysis of the effects of 'weberian' State". American Sociological Review, vol. 64, n² 5, 2000.

Evans, P.; RueschemeYer, D.; SKocPol, T. Bringing the State back in. Cambridge: Cambridge University Press, 1985.

FARIA, C. F. "Sistema deliberativo, formas de conexão e inclusão política: alcance teórico e prático". Revista Brasileira de Ciências Sociais, vol. 32, p. 1, 2017.

FERES, J. C.; ViLLATORO, P. "La viabilidade de erradicar la pobreza: un examen conceptual y metodológico". Santiago de Chile, Cepal, out. 2013.

FIANI, R. Cooperação e conflito: instituições e desenvolvimento econômico. Rio de Janeiro: Elsevier, 2011.

. "Arranjos institucionais e desenvolvimento: o papel da coordenação em estruturas híbridas". Texto para discussão, no 1815, Ipea, 2013.

FONSECA, I. F., et al. "Audiências públicas: fatores que influenciam seu potencial de efetividade no âmbito do poder Executivo federal". Revista do Serviço Público, vol. 64, n 1, p. 7-29, 2013.

Gomide, A. A.; Pereira, A. K.; Machado, R. "O conceito de capacidade estatal e a pesquisa científica". Sociedade e Cultura, vol. 20, p. 3-12, 2017.

HAIR, J. F., et al. Multivariate data analysis. Upper Saddle River: Prentice Hall, 2009.

HENDRIX, C. S. "Measuring State capacity: theoretical and empirical implications for the study of civil conflict". Journal of Peace Research, vol. 47, no 3, 2010. 
Herscovici, A. "Historicidade, entropia e não linearidade: algumas aplicações possíveis na ciência econômica". Revista de Economia Política, vol. 25, nº 3, p. 277-294, 2005.

Howlett, M.; RAmeSH, M. Studying public policy: policy cycles and policy subsystems. Oxford: Oxford University Press, 2003.

IBGE (Instituto Brasileiro de Geografia e Estatística). Indicadores IBGE: Sistema Nacional de Índice de Preços ao Consumidor - IPCA e INPC. Nota Técnica IBGE. Rio de Janeiro, julho de 2018.

Disponível em:

<ftp://ftp.ibge.gov.br/Precos_Indices_de_Precos_ao_Consumidor/IPCA/Fasciculo_Indicadores_IBGE /ipca-inpc_201807caderno.pdf >. Acesso em: 6 ago. 2018.

- Munic, Pesquisa de Informações Básicas Municipais - Perfil dos Municípios Brasileiros. Rio de Janeiro, 2005. Disponível em:

<https://ww2.ibge.gov.br/home/estatistica/economia/perfilmunic/default.shtm>. Acesso em: 5 abr. 2013.

IRELAND, T. D. "Educação de Jovens e Adultos como política pública no Brasil (2004-2010): os desafios da desigualdade e da diversidade". Rizoma freireano/Rhizome freirean, no 13, 2012. Instituto Paulo Freire de España. Disponível em: <http://www.rizomafreireano.org/educacao-dejovens>. Acesso em: 5 mar. 2017.

JACCOUD, L. Proteção social no Brasil: debates e desafios. In: Concepção e gestão da proteção social não contributiva no Brasil. Brasília: MDS/Unesco, p. 57-86, 2009.

JANN, W.; WEGRICH, K. Theories of the policy cycle. In: FISCHER, F., et al. Handbook of public policy analysis: theory, politics and methods. Boca Raton: CRC Press, 2007.

JANNuZZI, P. M. "Considerações sobre o uso, mau uso e abuso dos indicadores sociais na formulação e avaliação de políticas públicas municipais". Revista de Administração Pública, Rio de Janeiro, vol. $36, \mathrm{n}^{\circ} 1$, p. 51-72, 2002.

. "Eficiência econômica, eficácia procedural ou efetividade social: três valores em disputa na avaliação de políticas e programas sociais". Desenvolvimento em Debate (INCT/PPED), vol. 4, p. 117-142, 2016.

Johnson, C. A. The industrial policy debate. Califórnia: ICS Press, 1985.

. The developmental State: odyssey of a concept. In: Woo-Cumings, M. The developmental State. Ithaca: Cornell University Press, 1995.

KoCher, M. A. "State capacity as a conceptual variable". Yale Journal of International Affairs, Spring/ Summer, p. 137-145, 2010. Disponível em: <http://yalejournal.org/wpcontent/uploads/2010/09/105212kocher.pdf>. Acesso em: 12 ago. 2017.

LAVALle, A. G.; SzWAKo, J. "Sociedade civil, Estado e autonomia: argumentos, contra-argumentos e avanços no debate". Opinião Pública, vol. 21, no 1, p. 157-187, 2015.

Lavalle, A. G.; Voigt, J.; Serafim, L. "O que fazem os conselhos e quando o fazem? Padrões decisórios e o debate dos efeitos das instituições participativas". Dados, vol. 59, n 3, p. 609-650, 2016.

LEFTWICH, A. "Bringing politics back in: towards a model of developmental State". The Journal of Development Studies, vol. 31, n 3, p. 400-427, 1995.

Forms of democratic developmental States. Democratic practices and development capacity. In: RoBInson, M.; WHITE, G. (eds.). The democratic developmental State. Political and institutional design. Oxford: Oxford University Press, 1998. 
LI, B. Q. H.; FONG, A.; LU, M. "Assessing record linkage between health care and vital statistics databases using deterministic methods". BMC, vol. 6, n 48. Disponível em:

<http://www.biomedcentral.com/1472-6963/6/48>, 2007. Acesso em: 9 jul. 2014.

LIST, G. F. Sistema nacional de economia política. Trad. Luiz João Baraúna. São Paulo: Nova Cultural, 1986.

ME (Ministério do Esporte). Sistema de Monitoramento e Avaliação do Programa Segundo Tempo. Relatório Técnico. Ministério do Esporte. Brasília, 2010. Disponível em:

<http://portal.esporte.gov.br/arquivos/snee/segundoTempo/sistemaMonitoramentoAvaliacaoProgra masEsporte.pdf $>$. Acesso em: 9 abr. 2013.

MEC (Ministério da Educação). Relatório de Gestão: Exercício 2009. Secretaria de Educação Continuada, Alfabetização e Diversidade. MEC, Brasília, 2010. Disponível em:

$<$ http://portal.mec.gov.br/index.php?option=com_content\&view=article\&id=14942\&Itemid=1166> . Acesso em: jan. 2013.

MeIRELLES, D. S. "Teorias de mercado e regulação: por que os mercados e o governo falham?". Cadernos Ebape, vol. 8, n 4, p. 644-660. Disponível em:

<http://www.scielo.br/scielo.php?pid=S1679-39512010000400006\&script=sci_arttext>, 2010. Acesso em: 10 maio 2016.

MinA (Ministério da Integração Nacional). Relatório de Gestão do exercício de 2012 apresentado aos órgãos de controle interno e externo como prestação de contas anual a que esta unidade está obrigada nos termos do art. 70 da Constituição Federal, elaborado de acordo com as disposições da IN TCU no 63/2010, da DN TCU no 119/2012 e da Portaria TCU no 150/2012. Brasília, 2012. Disponível em:

<http://www.integracao.gov.br/documents/10157/4298769/Relat\%C3\%B3rio+de+Gest\%C3\%A3oSECEX-2012.pdf/d97c5b4b-a449-4e67-b448-235020bc255d>. Acesso em: 18 abr. 2015.

Miguel, L. F. "Impasses da accountability: dilemas e alternativas da representação política". Revista de Sociologia e Política, vol. 25, p. 25-38, 2005.

MONTEIRO, L. "Reforma da administração pública e carreiras de Estado: o caso dos especialistas em políticas públicas e gestão governamental no Poder Executivo federal". Revista de Administração Pública, vol. 47, no 5, 2013.

MPOG. SIGPlan - Sistema de Informações Gerenciais e de Planejamento. Módulo de avaliação dos PPAs de 2002 a 2010. Ministério do Planejamento, Orçamento e Gestão (MPOG).

NORTH, D. "The role of institutions in economic development". United Nations Economic Comission for Europe. Geneva, Switzerlandm, 2003.

NUNES, E. A gramática política do Brasil. 2a ed. Rio de Janeiro: Jorge Zahar, 1997.

OliveirA, V. E.; ABRUcio, F. L. "Entre a política e a burocracia: a importância dos burocratas de nível médio para a produção de políticas públicas em saúde e educação". Artigo apresentado no $35^{\circ}$ Encontro Anual da Anpocs, Caxambu, MG, 2011.

OlLAIK, L.; Medeiros, J. J. "Instrumentos governamentais: reflexões para uma agenda de pesquisas sobre implementação de políticas públicas no Brasil". In: Anais do Encontro de Administração Pública e Governança da Anpad, 4. Anpad, Vitória, 2010.

PAinter, M.; Pierre, J. Unpacking policy capacity: issues and themes. In: PAinter, M.; PIERre, J. (eds.). Challenges to State policy capacity. Basingstoke: Palgrave Macmillan, 2005.

PERES, U. D. "Custos de transação e estrutura de governança no setor público". Revista Brasileira de Gestão de Negócios, vol. 9, n²4, p. 15-30, 2007. 
Peruzzotti, E. Media scandals and social accountability: assessing the role of the Senate scandal in Argentina. In: Peruzzotti, E.; SMulovitz, C. Enforcing the rule of law: social accountability in the new Latin American democracies. Pittsburgh: Pittsburgh Press, 2007.

QUINTÃo, T. T.; CUNHA, E. S. M. "Fala que eu te escuto: ouvidorias parlamentares e o seu potencial democrático". Revista de Sociologia e Política, vol. 26, nº 66, p. 125-143, 2018.

PIRES, R. Burocracias, gerentes e suas "histórias de implementação": narrativas do sucesso e fracasso de programas federais. In: FARIA, C. A. P. (org.). Implementação de políticas públicas: teoria e prática. Belo Horizonte: Editora PUC Minas, p. 182-220, 2012.

PIRES, R.; Gomide, A. A. "Governança e capacidades estatais: uma análise comparativa de programas federais". Revista de Sociologia e Política, vol. 24, p. 121-143, 2016.

PIRES, R. R. C.; VAZ, A. C. N. "Para além da participação: interfaces socioestatais no governo federal". Lua Nova, no 93, p. 61-91, 2014.

PogrebinsChi, T. "Democracia pragmática". Dados, Revista de Ciências Sociais, vol. 53, no 3, 2010.

Przeworski, A.; Stokes, S.; MAnin, B. (eds.). Accountability, and representation. Cambridge: Cambridge University Press, 1999.

RAMESH, M.; Howlett, M. "Achille's heels of governance: critical capacity deficits and their role in governance failures". Regulation and Governance, vol. 10, no 4, 2016.

RAUCH, J.; EVANS, P. "Bureaucratic structure and bureaucratic performance in less developed countries". Journal of Public Economics, vol. 75, n 1, 2011.

Ribeiro, L. C., et al. "Science in the developing world: running twice as fast?". Computing in Science and Engineering, vol. 8, 2006.

RibeIRo, U. C., et al. "Experiências de monitoramento dos resultados de conferências nacionais: elementos para a discussão sobre efetividade da participação na gestão pública". Revista do Serviço Público, vol. 66, p. 55-74, 2015.

Santos, B. S.; Avritzer, L. Para ampliar o cânone democrático. In: Santos, B. S. (org.). Democratizar a democracia. Rio de Janeiro: Civilização Brasileira, 2003.

SANTOS, L. A. S.; MARQueS, D. B. "Burocracia e economia dos custos de transação: uma análise da relação entre a Universidade Federal de Pernambuco e a Refinaria Abreu e Lima". Revista Administração Pública e Gestão Social, vol. 7, nº 1, 2015.

SATYRo, N. D.; Cunha, E. S. M. "The path of Brazilian social assistance policy post-1988: the significance of institutions and ideas". Brazilian Political Science Review, vol. 8, p. 80-109, 2014.

Schumpeter, J. A. Capitalism, socialism and democracy. Londres: Alien\&Unwin, 1976.

Sintomer, I. O poder ao povo: júris de cidadãos, sorteio e democracia participativa. Belo Horizonte: UFMG, 2010.

Skocpol, T. States and social revolutions: a comparative analysis of France, Russia, and China. Cambridge: Cambridge University Press, 1979.

SkocPol, T.; AMENTA, E. "States and social policies". Annual Review of Sociology, vol. 12, p. 131$157,1986$.

TenóRIo, F. G. "(Neo)tecnocratas ou (neo)bobos? Eis a questão". O\&S. Organizações \& Sociedade, Salvador, vol. 10, no 26, p. 107-117, 2003.

THIES, C. G. "Of rulers, rebels, and revenue: State capacity, civil war onset, and primary commodities". Journal of Peace Research, vol. 47, no 3, 2010. 
TCU (Tribunal de Contas da União). Monitoramento - Natureza Operacional - Programa Brasil Alfabetizado. Secretaria de Fiscalização e Avaliação de Programas de Governo 006.555/2006-2, junho de 2006. Disponível em:

<https://portal.tcu.gov.br/lumis/portal/file/fileDownload.jsp?inline=1\&fileId=8A8182A14D92792C01 4D9283E8B1148E>. Acesso em: 9 mar. 2015.

VAZ, A. C. N. Ação estatal, desenvolvimento e democracia: elementos para uma discussão na contemporaneidade. In: CARDoso JR., J. C. (org.). Planejamento Brasil século XXI. Brasília: Ipea, 2015.

- "Capacidades burocráticas e políticas no âmbito da gestão pública: inferindo limites e possibilidades para a gestão pública operacional". Revista Brasileira de Planejamento e Orçamento, vol. 6, no 2, 2016.

VAZ, A. C. N., et al. "Estudos avaliativos com base na integração de registros administrativos: a experiência de integração do Cadastro Único para Programas Sociais, Programa Bolsa Família e Sistema de Vigilância Alimentar e Nutricional". Cadernos de Estudos - Secretaria de Avaliação e Gestão da Informação, vol. 17, p. 38-49, 2014.

VIDAL, D. G.; FARIA FILHO, L. M. "História da educação no Brasil: a constituição histórica do campo (1880-1970)". Revista Brasileira de História, São Paulo, vol. 23, no 45, p. 37-70, jul. 2003.

WAMPLER, B. "When does participatory democracy deepen the quality of democracy?". Comparative Politics, vol. 41, no 1, 2008.

WeBER, M. Ensaios de sociologia. Belo Horizonte: Editora LTC, 2002.

WhITE, G. Constructing a democratic developmental State. In: RoBinson, M.; WHITE, G. (eds.). The democratic political State. Oxford: Oxford University Press, 1998.

WISE, L. R. "Bureaucratic posture: on the need for a composite theory of bureaucratic behavior". Public Administration Review, vol. 64, no 6, p. 669-680, November-December 2004.

WooldRIDGE, J. M. Econometric analysis of cross section and panel data. $2^{\mathrm{a}}$ ed. Cambridge, MA: MIT Press, 2010.

Yin, R. K. Estudo de caso - planejamento e métodos. Porto Alegre: Bookman, 2001. 


\begin{abstract}
Decision making, political centrality, and bureaucratic entropy: mitigating transactional costs in public management

This article investigates the effects of bureaucratic and sociopolitical capacities on the processes of formulating and implementating public policies. This work carries out a comparative study of four institutions at the level of the federal executive power in Brazil. By tracing the institutions' respective historical paths, this work seeks explanations for their current situations in terms of their aforementioned capacities. In addition, a study of programs developed by these institutions is carried out, investigating how each institution's current capacity tends to influence the development of these programs. The analysis shows that the thematic area of action of the institutions has an important influence on their potential development of capacities. In addition, the joint development of these capacities seems generally to lead to satisfactory results in the institutions' development of policies.
\end{abstract}

Keywords: state capabilities; bureaucratic capabilities; political capabilities; social-state interfaces; socioeconomic development

\title{
Resumen
}

Dispersión decisoria, centralidad política y entropía burocrática: mitigando costos transaccionales en la gestión pública

El artículo investiga los impactos de capacidades políticas y burocráticas en los procesos de formulación e implementación de políticas públicas. Se realiza un estudio comparativo de cuatro instituciones del poder Ejecutivo Federal brasileño, buscando, a través de sus respectivos itinerarios históricos de formación, elementos explicativos para su situación actual en términos de esas capacidades. En adición, se realiza un estudio de programas desarrollados por esas propias instituciones, entregando en qué sentido su status corriente de capacidades tiende a influir en el desarrollo de esos programas. El análisis evidencia que el área temática de actuación de los órganos tiene una importante influencia en su potencial de desarrollo de las capacidades estudiadas. Además, el desarrollo conjunto de estas últimas parece llevar a la obtención de resultados satisfactorios en el desarrollo de políticas por esos órganos.

Palabras clave: capacidades estatales; capacidades burocráticas; capacidades políticas; las interfaces socioestatales; desarrollo socioeconómico

\section{Résumé}

Dispersion des décisions, centralité politique et entropie bureaucratique: atténuer les coûts de transaction en gestion publique

L'article examine l'impact des capacités politiques et bureaucratiques sur les processus de formulation et de mise en œuvre des politiques publiques. Une étude comparative de quatre institutions de I'exécutif fédéral brésilien est réalisée, cherchant, à travers leurs parcours de formation historiques respectifs, des éléments explicatifs de leur situation actuelle en termes de capacités. En outre, une étude est menée sur les programmes développés par ces institutions elles-mêmes, dans lesquelles l'état actuel de leurs capacités tend à influencer le développement de ces programmes. L'analyse montre que le domaine thématique de performance des organes a une influence importante sur leur potentiel de développement des capacités étudiées. En outre, le développement conjoint de ces derniers semble conduire à des résultats satisfaisants dans l'élaboration des politiques de ces organismes.

Mots-clés: capacités d'état; capacités bureaucratiques; capacités politiques; interfaces d'état social; développement socioéconomique 